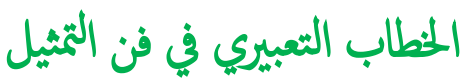

غادة عبد الستار عواد

كلية الفنون الجميلة/جامعة بغداد

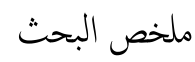

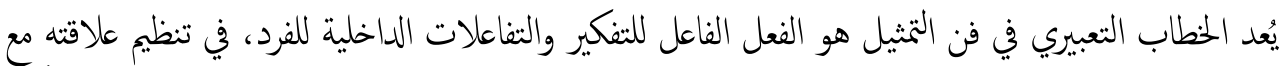

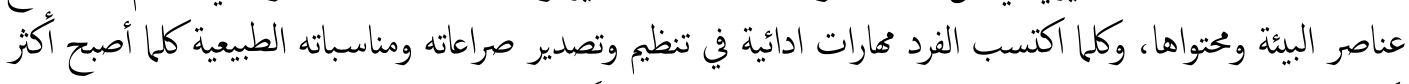

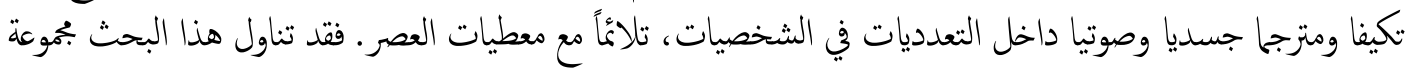

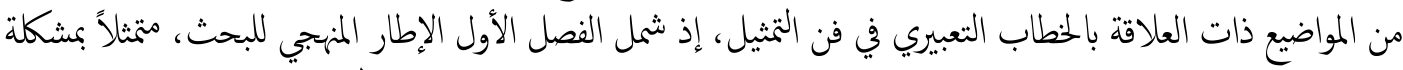

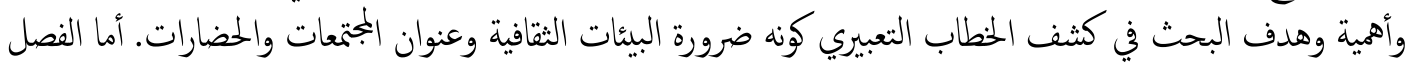

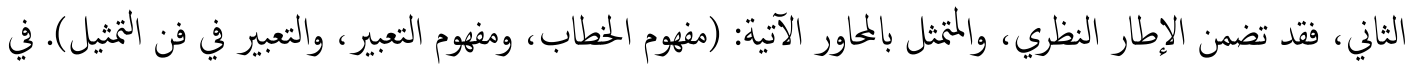

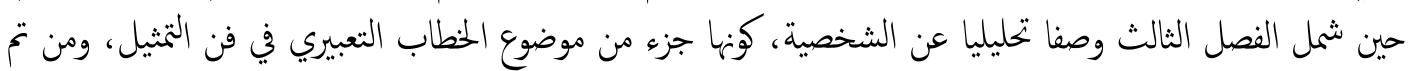

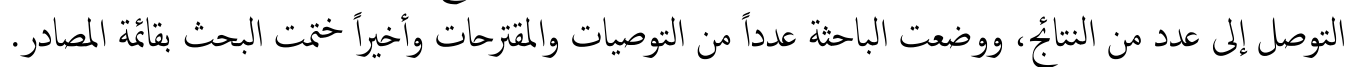
الفصل الوول

مشكلة البحث

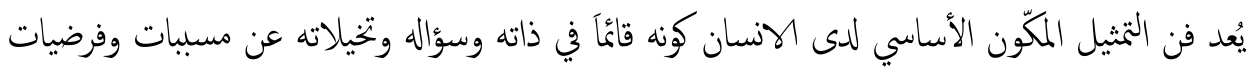

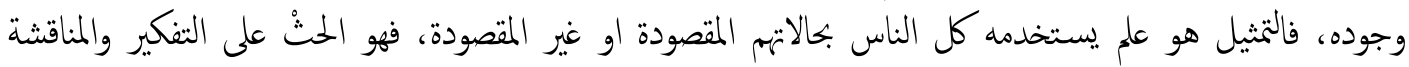

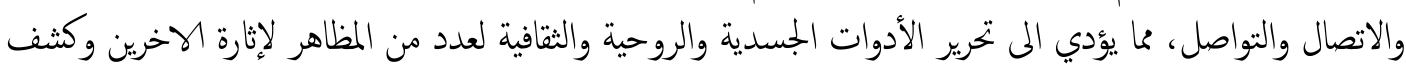

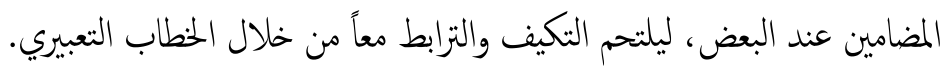

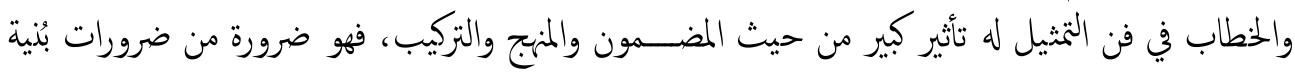

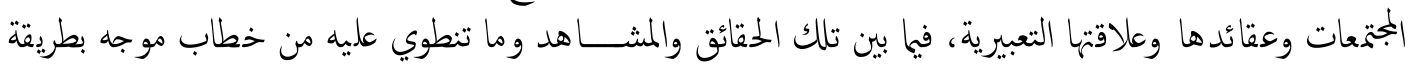

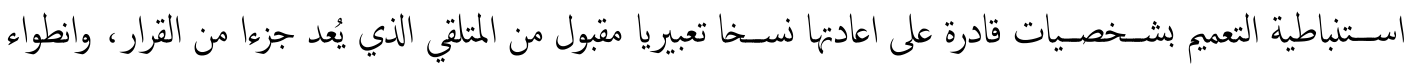

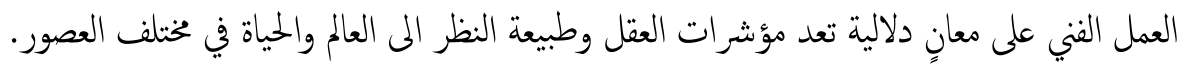

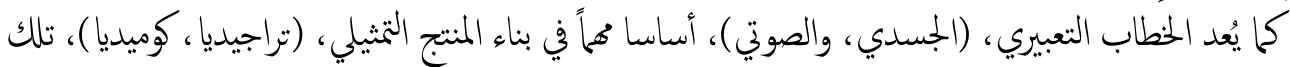

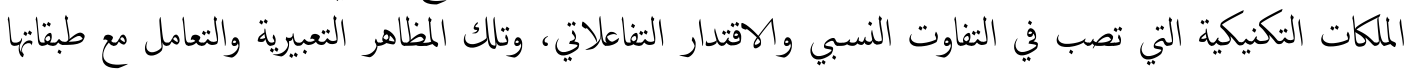

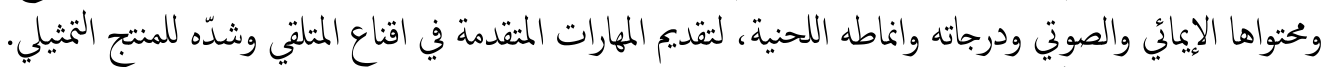

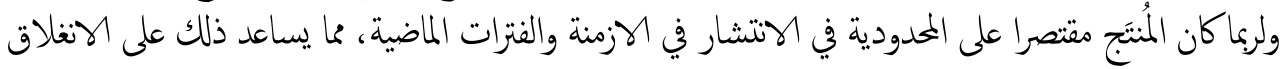

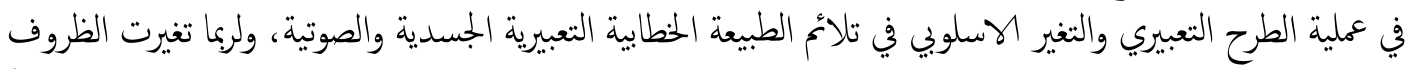

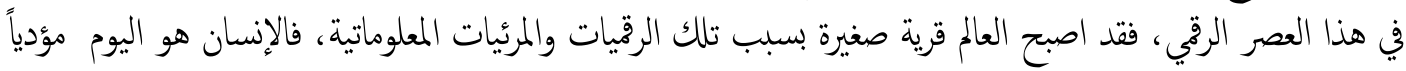

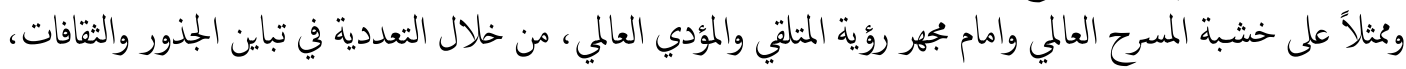

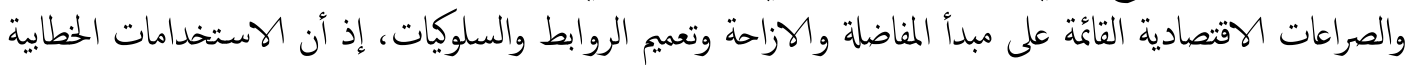

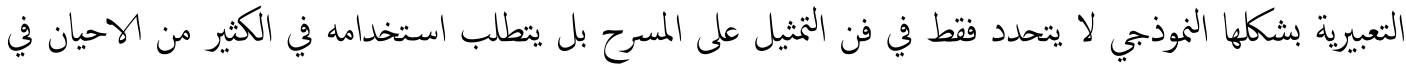

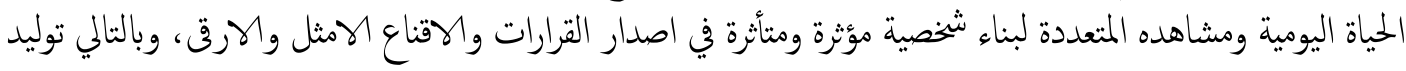


الخبرات والتجارب الحضارية لواقع البيئات القريبة من المنتلي ايناكان، وهذا ما دعا الباحثة لعرض مشكلة هذه الدراسة

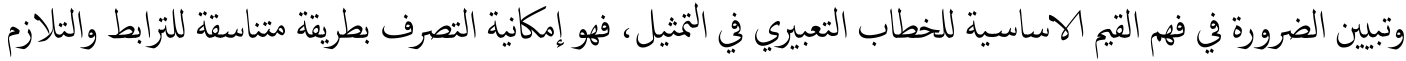

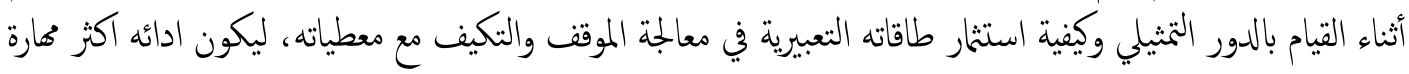

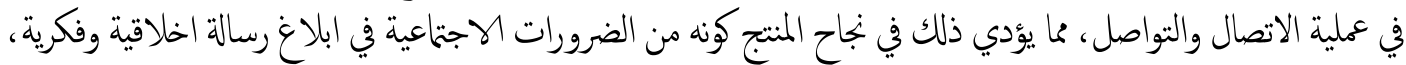

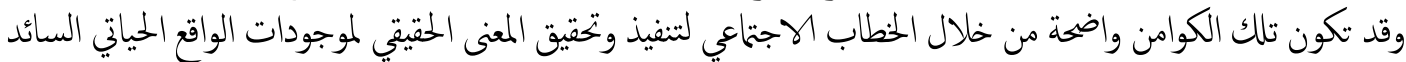

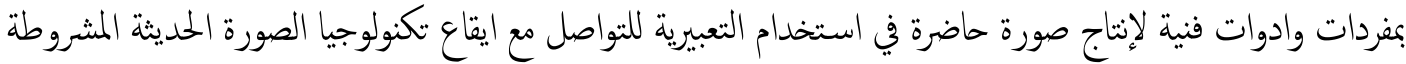

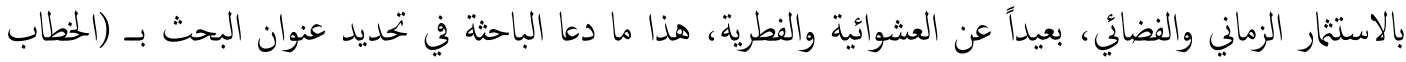

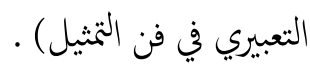
اهمية البحث تكمن أهمية البحث في: -

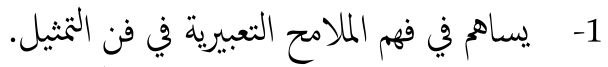

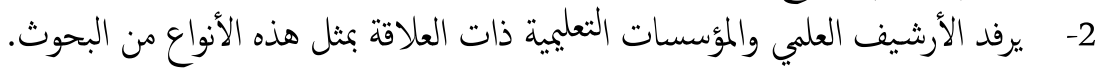

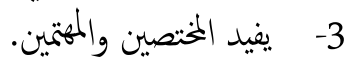

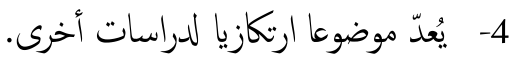
هدف البحث بهدف البحث الحالي في كثف الخطاب التعبيري في فن التمثيل، كونه ضرورة البيئات الثقافية وعنوان المجتمعات والحضارات. حدود البحث الحد الموضوعي: الخطاب التعبيري في فن التمثيل.

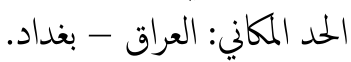
تحديد المصطلحات تناولت الباحثة أهم المصــطلحات الواردة ذات العلاقة المباشرة بضــمون البحث، بغية صــياغة تعريف إجرائي

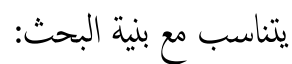
أولامالخطاب Discourse

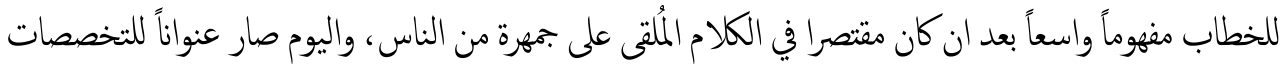

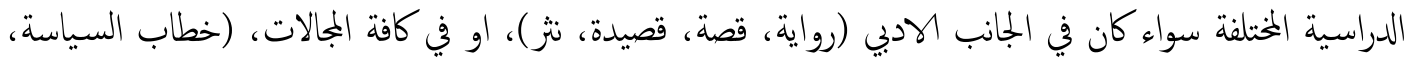

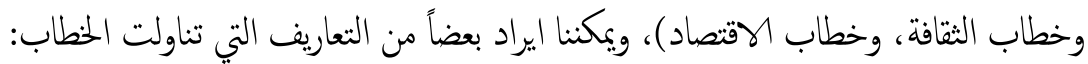

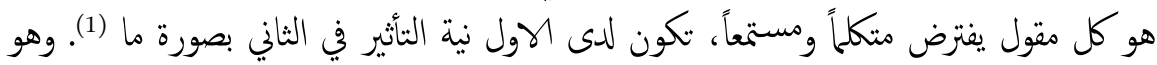

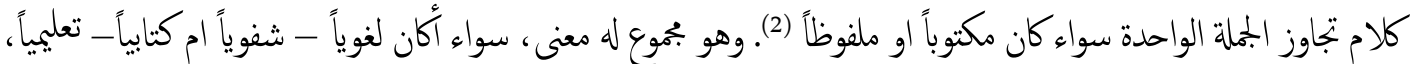

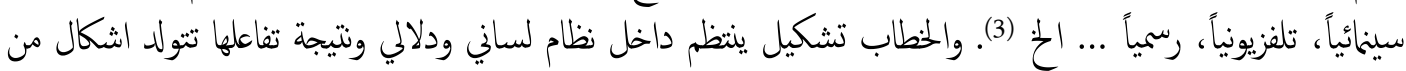


الخطاب لكلٍ خصوصيته التي تنجز داخل شروط التواصل (4) . ويعتبر الخطاب عملاً اجتماعياً تعتمد فيه العبارة أي الكلمات

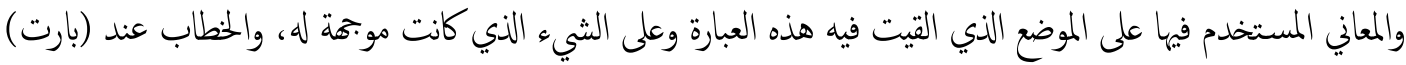

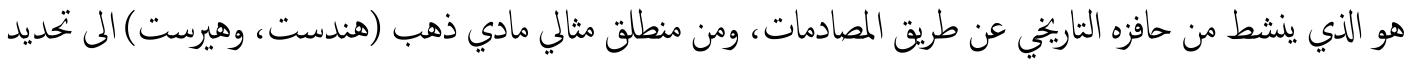

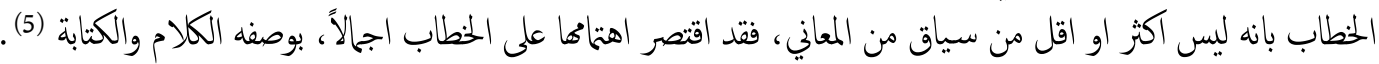
ثانيا -التعبير Expression

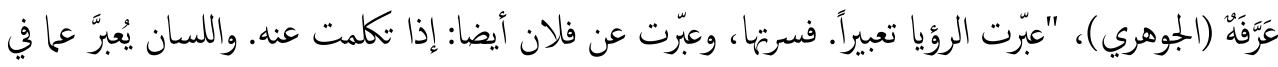

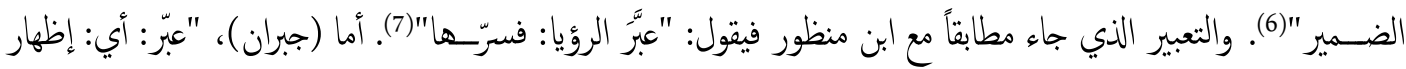

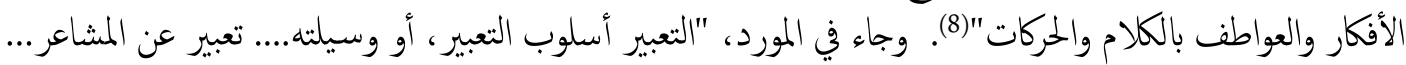

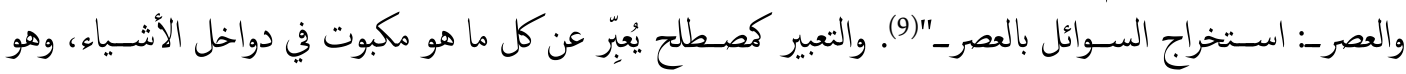

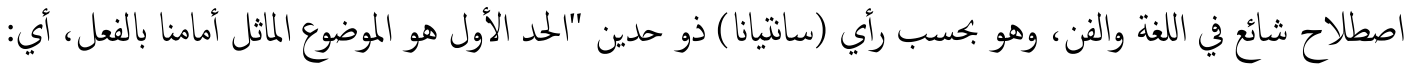

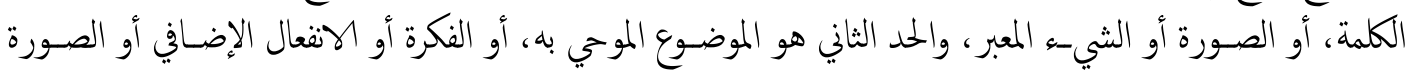

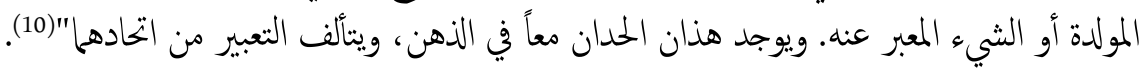
الفصل الثاني / الإطار النظري

مفهوم الخطاب

يُعد الخطاب مصدراً أساسياً في فهم حقبة زمنية ما، ضمن ادبيات النقد الادبي والفني، فهو يساهم معرفياً

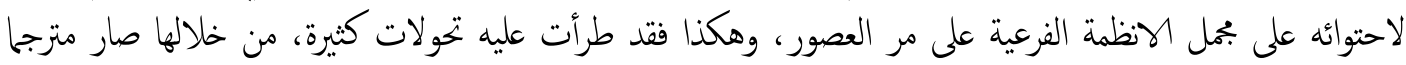

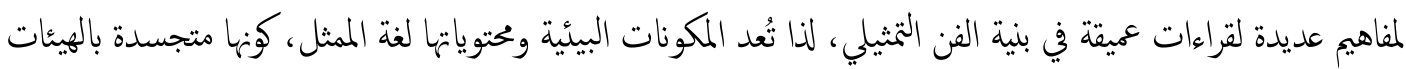

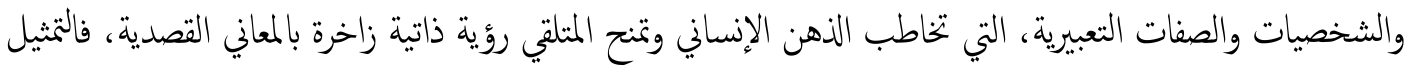

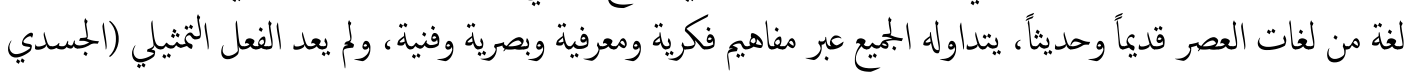

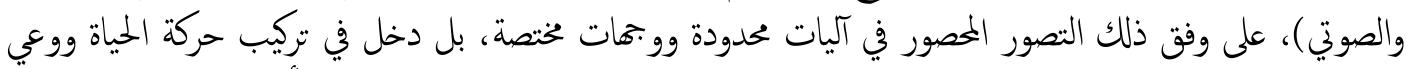

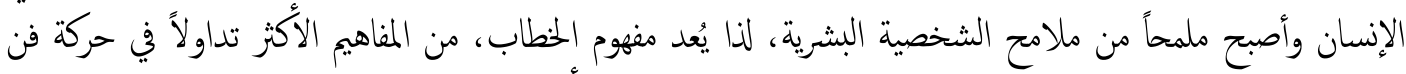

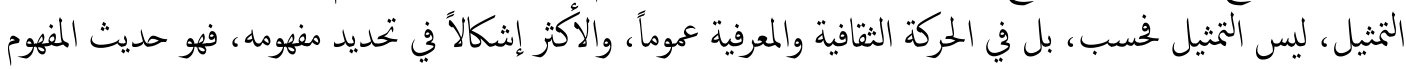

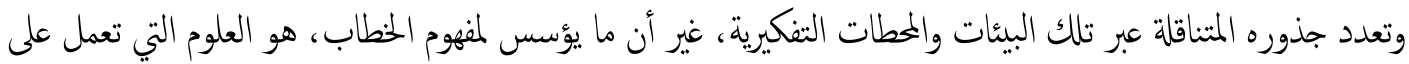

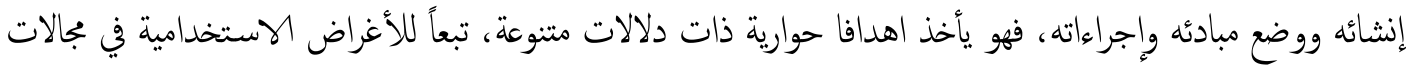
المعرفة التي يُستخدم فيها ويقترن بهائه .

(4) الاعسم، باسم عبد الامير: مفهوم الشكل والخطاب المسرحي، العدد الاول، بغداد: (وزارة التعليم العالي والبحث العلمي، كلية الفنون الجميلة)، 2001م، صي

ص35.

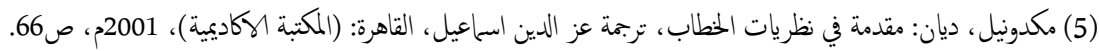

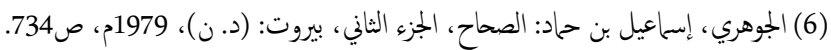

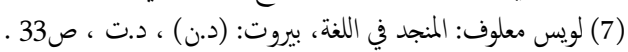

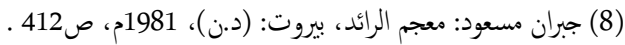

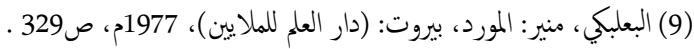

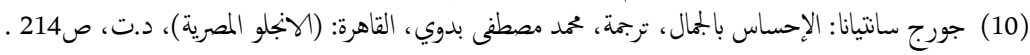


وقد اختلف مفهوم الخطاب عبر العصور فنثلاً تميز الفن اليوناني بالمقدرة الهائلة على تصوير العالم المرئي وأصبح

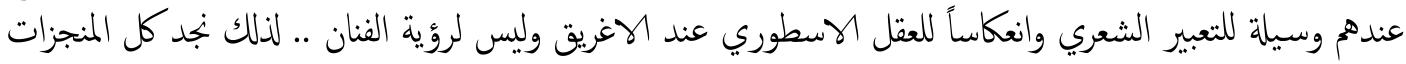

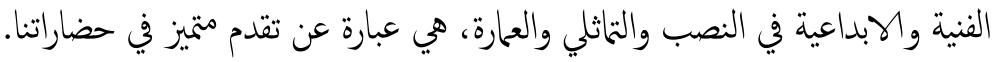

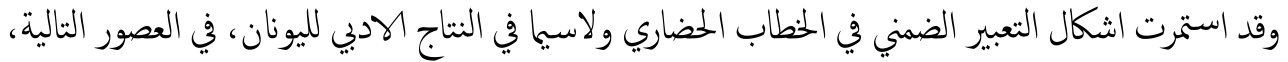

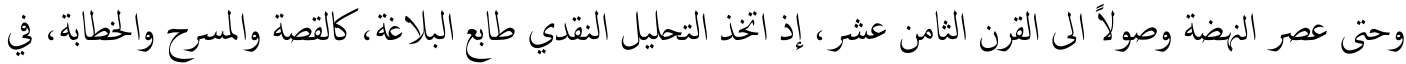

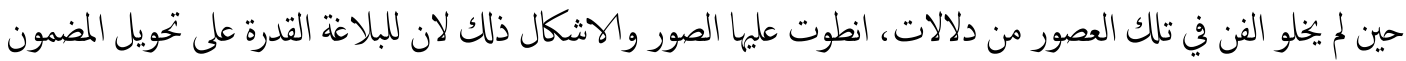

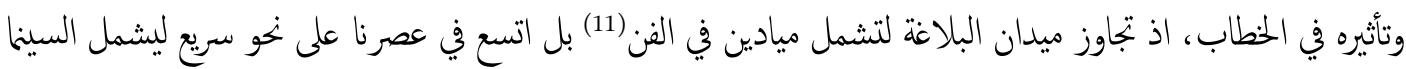

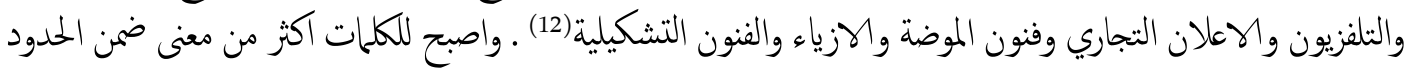

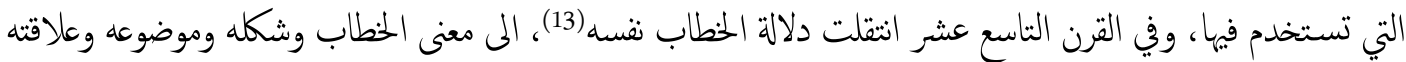

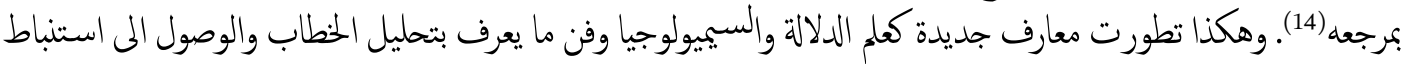

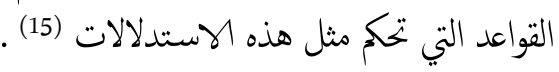

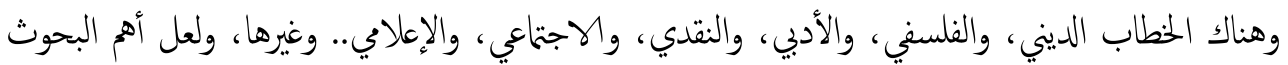

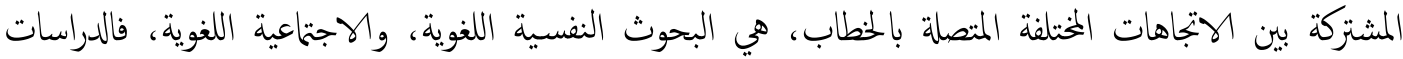

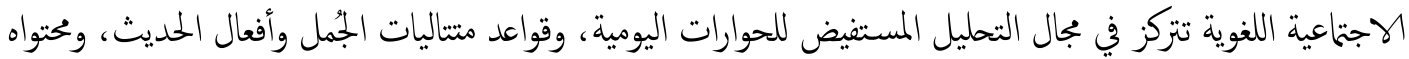

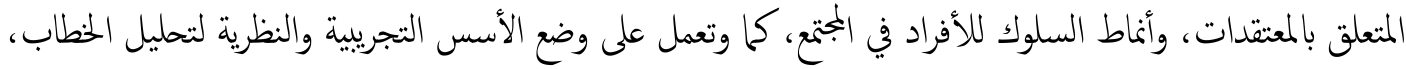

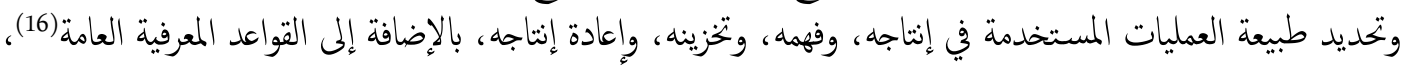

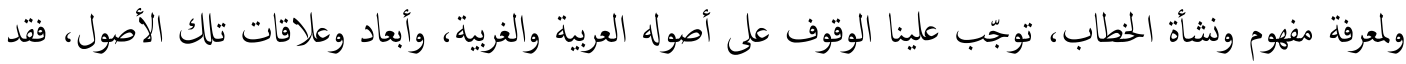

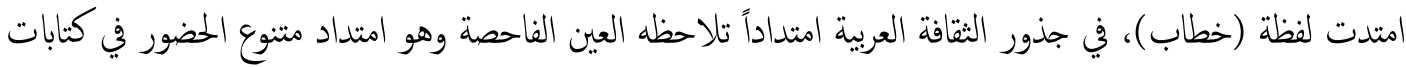

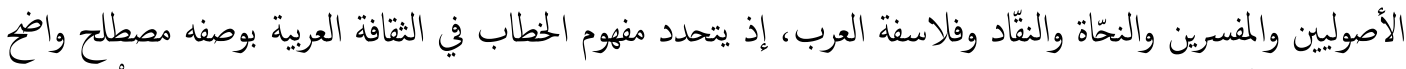

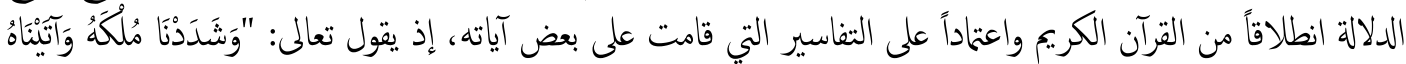

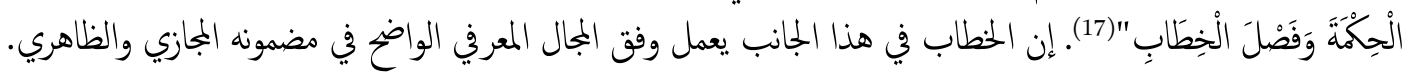

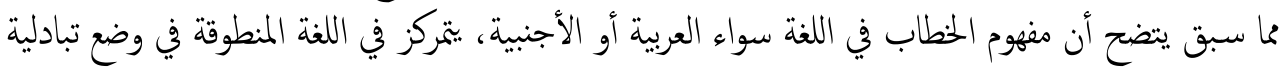

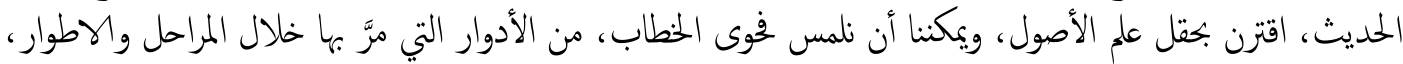

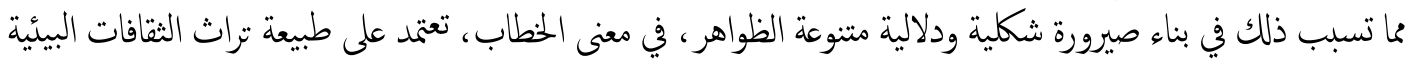

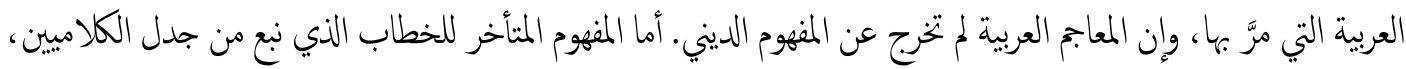

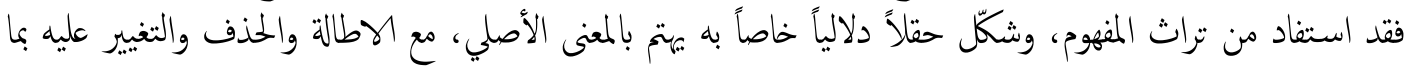

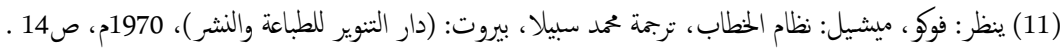

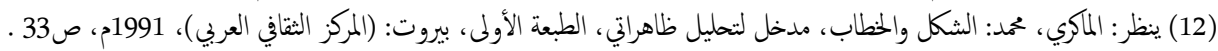

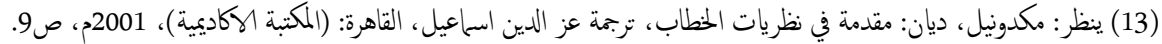


يتلاءم مع الشكل الاخير في استخدام الخطاب، رغز الظروف البيئة التي تهدد قوامه بعدم الاستقرار، هو استبدال مدلولاته العربية بالغربية. مفهوم التعبير

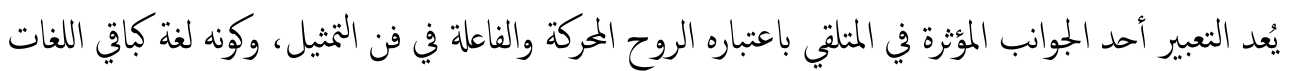

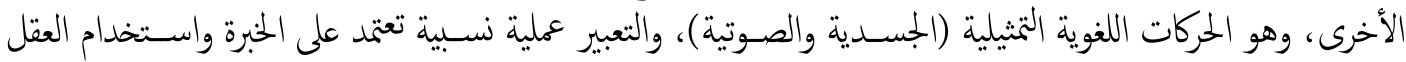

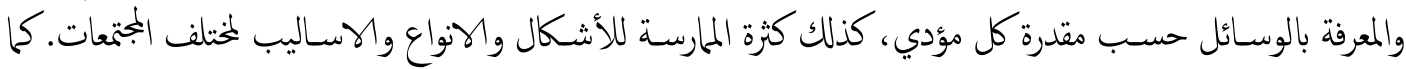

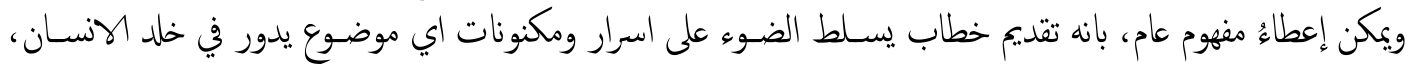

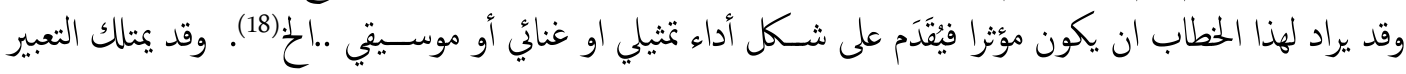

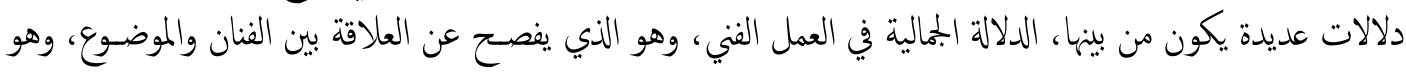

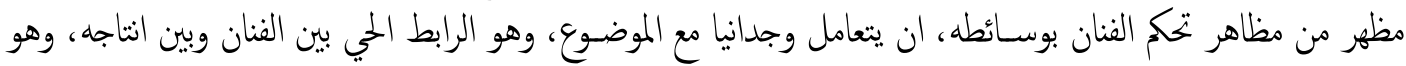

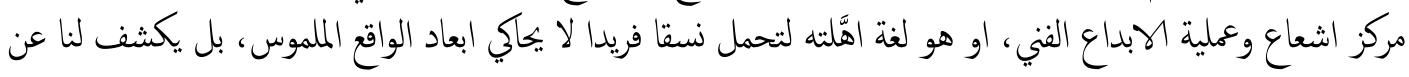

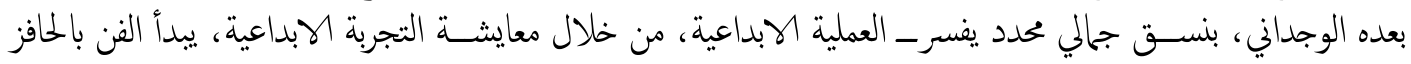
الجمالي وثرة هذا الحافز هو التعبير الفني (19).

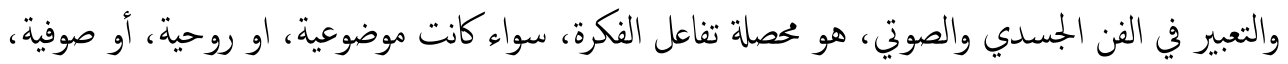

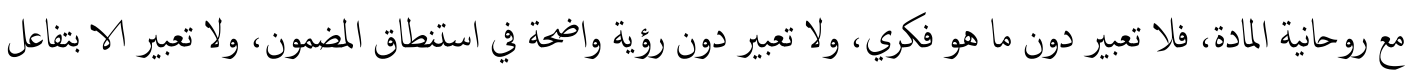

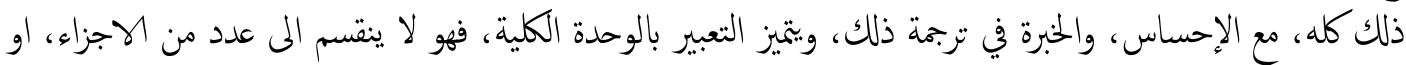

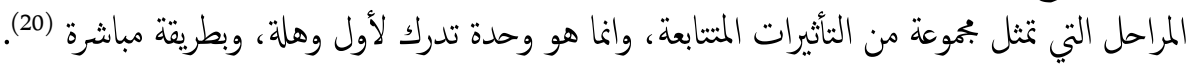

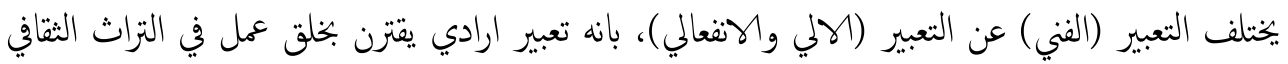

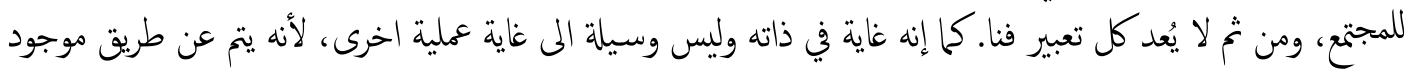

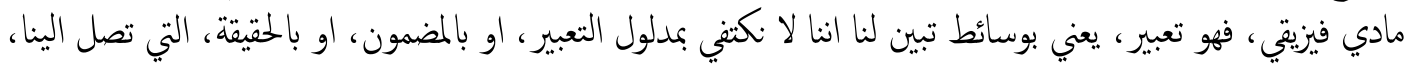

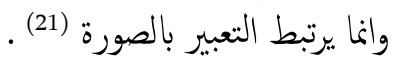

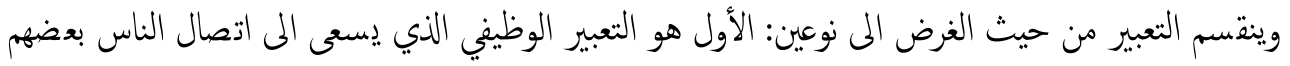

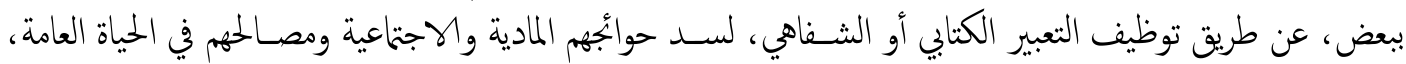

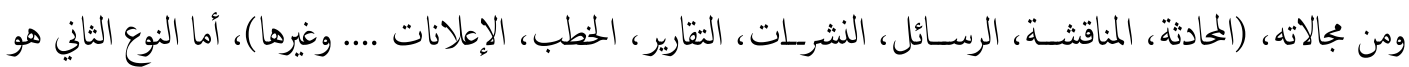

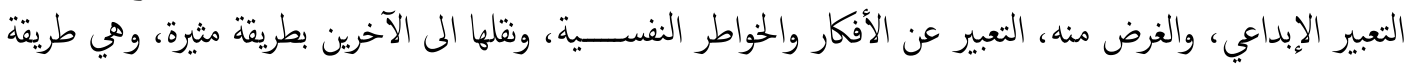

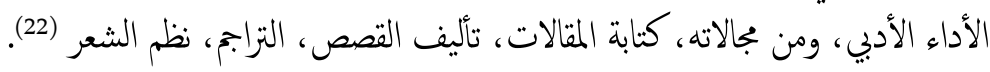

(18) الجابري، وليد حسن عبد الحسين: التوظيف الفني للنغم والتعبير في تجويد القرآن الكريم، أطروحة دكتوراه غير منشورة، بغداد: (جامعة بغداد، كلية الفنون

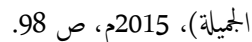

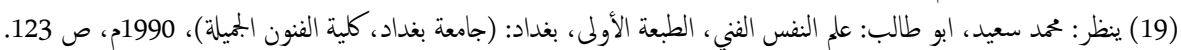

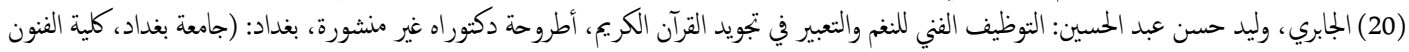

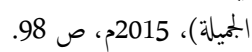

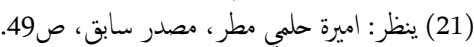
(22) ينظر: الروضان، عبد الكريم بن روضان: أثر استخدام المراحل المحس للكتئابة في تنمية القدرة على التعبير الكتابي، رسالة ماجستير غير منشورة، السعودية:

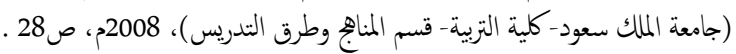


،تتمثل قيمة العمل التمثيلي في تنظيم عناصره التعبرية، او ما نسميه عناصره التريبية، وما ينتج بنيها من علاقات

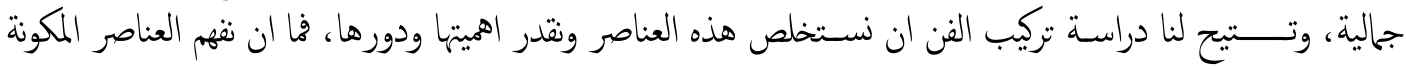
للعمل وعلاقتها المتبادلة ، وبذلك تزداد الجمالية حدّة (23).

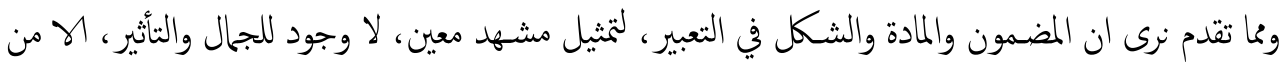

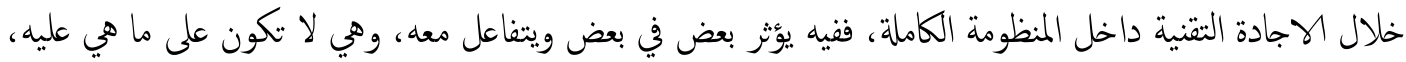

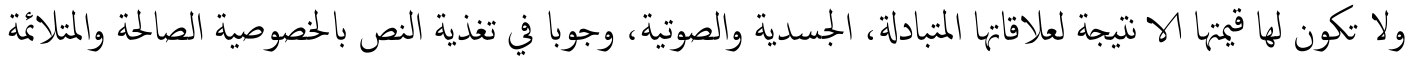

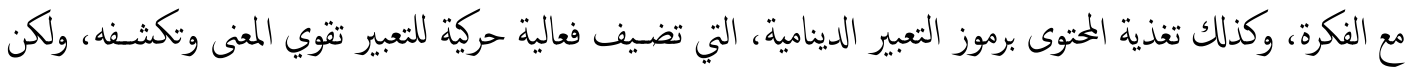

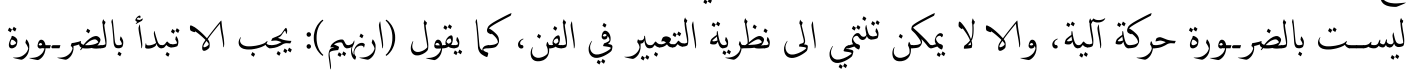

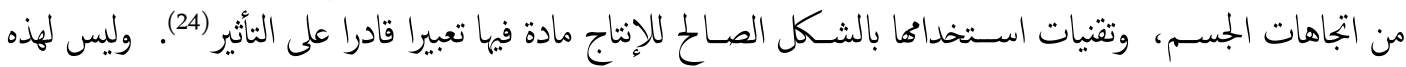

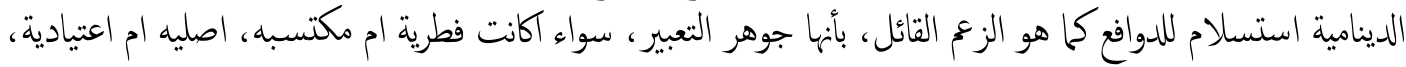

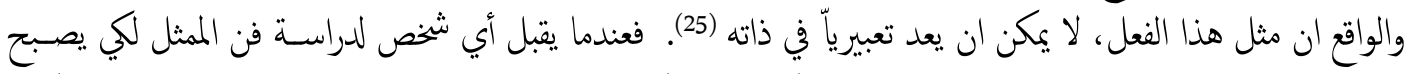

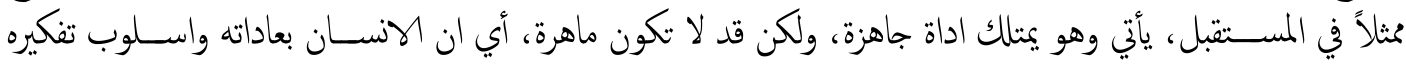

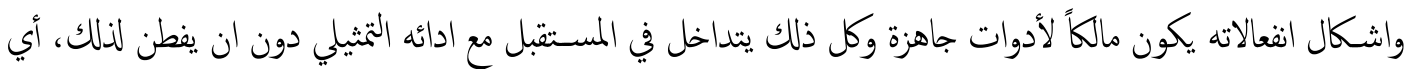

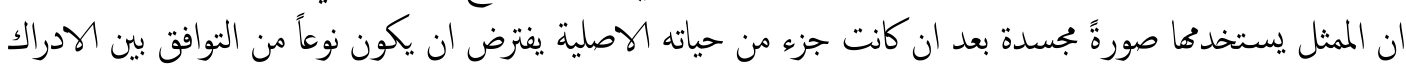

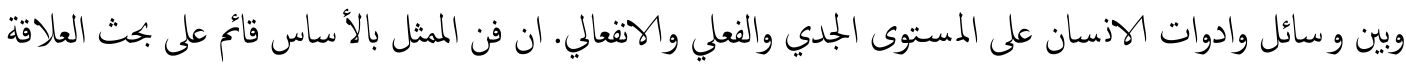

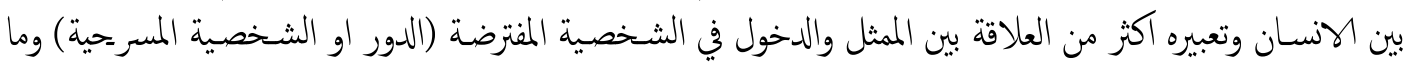

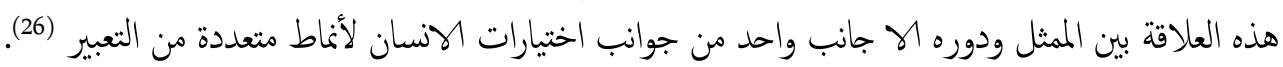

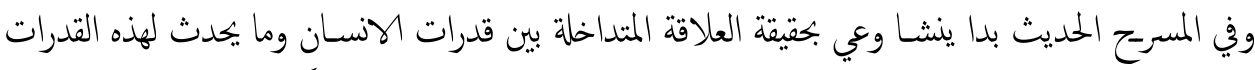

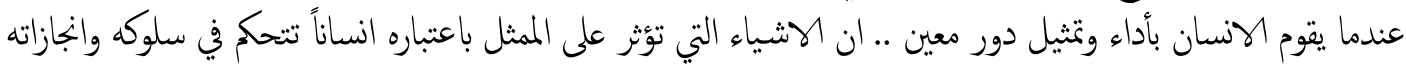
على خشبة المسرح.

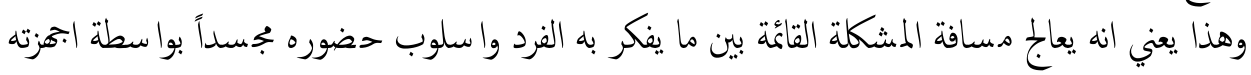

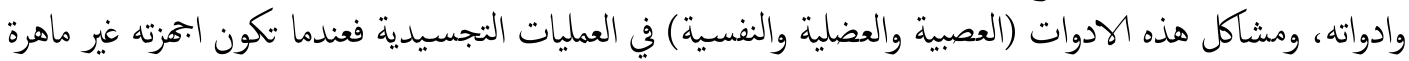

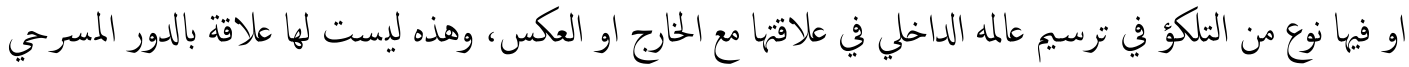

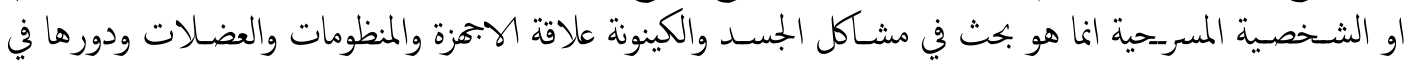

عملية الحضور الذاتي والهوية (27).

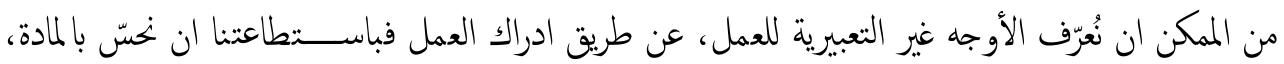

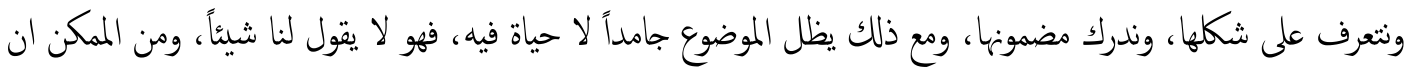

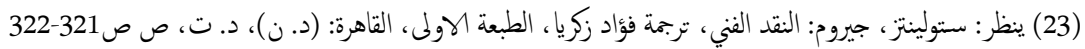

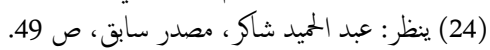
(25) ينظر: جون ديوي: الفن خبرة، ترجمة، زكريا ابراهيم، مراجعة زكي نجئ نجيب محمود، نيويورك، القاهرة: (دار النهضة العربية، الاشتراك مع مؤسسة فرانكلين

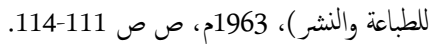
(26) ينظر: هيثم عبد الرزاق علي: محارات فن الاداء في التمثيل والخطاب الهنتماعي، أطروحة دكتوراه غير منشورة، بغداد: (جامعة بغداد، كلية الفنون الجميلة،

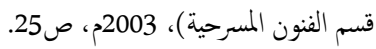

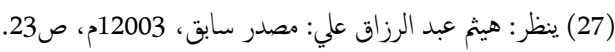




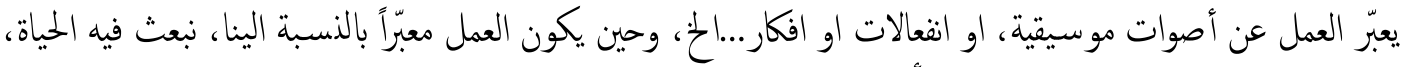

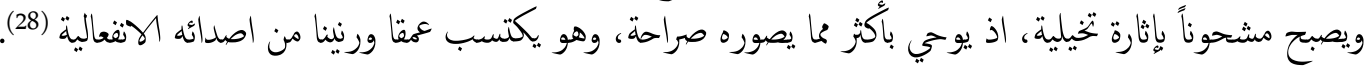

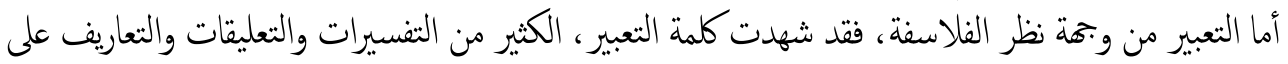

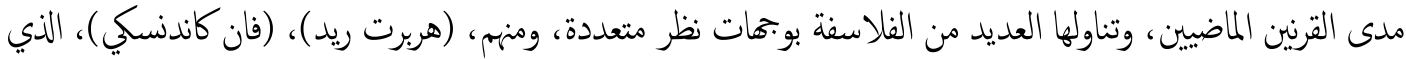

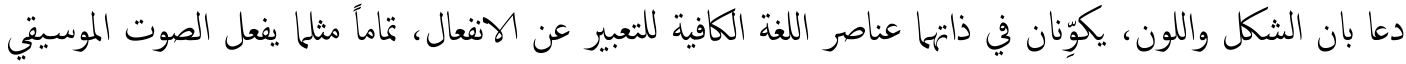

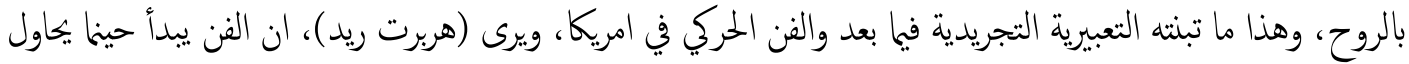

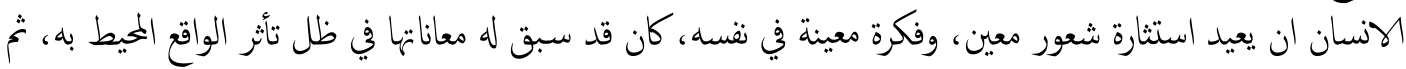

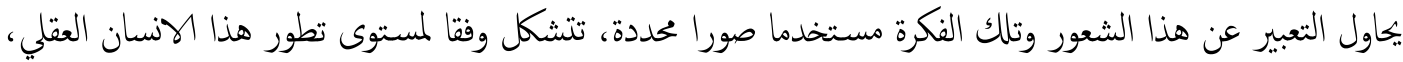

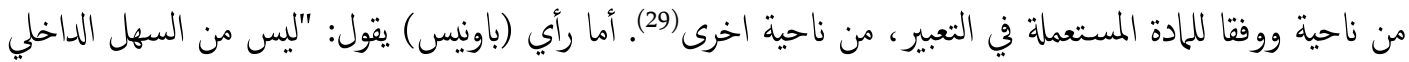

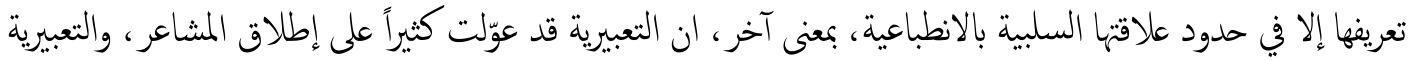

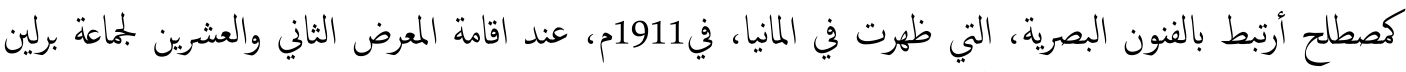

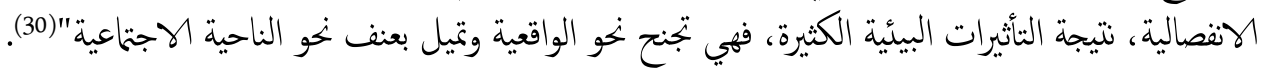

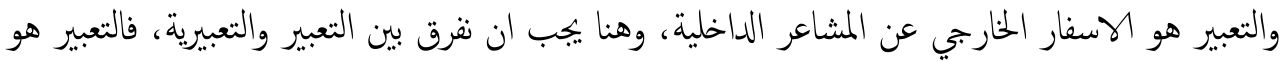

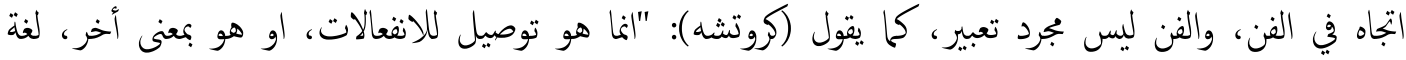

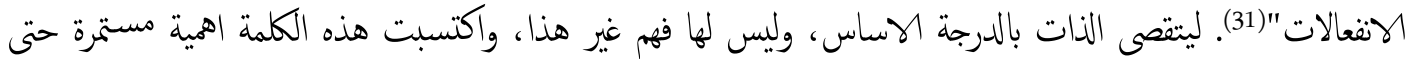

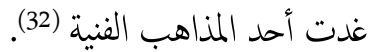
فالتعبير هو كثف لمعاني ذات العلاقات المرتبطة على الوجه الذي اقتضاه العقل ، وهذه العلاقات تكون نظاما

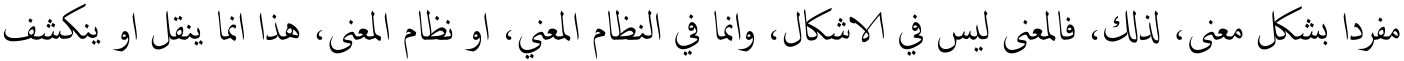

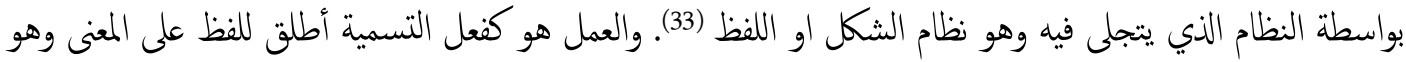

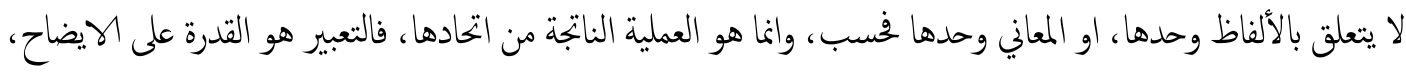

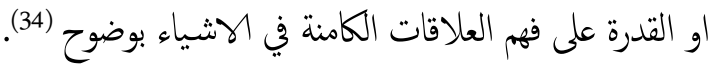

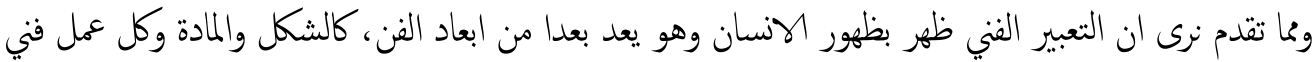

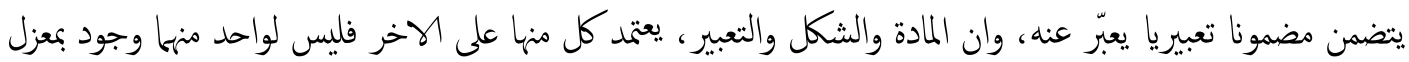

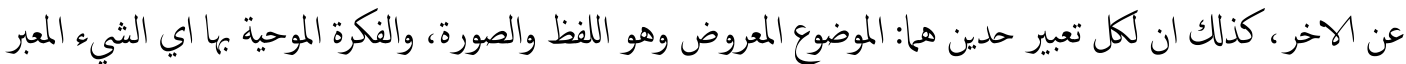

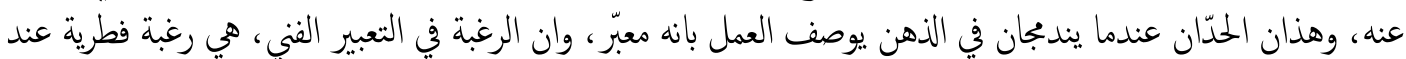

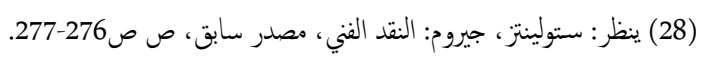

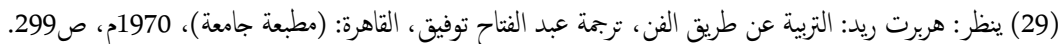

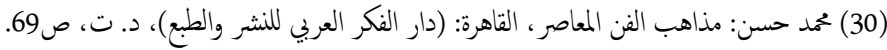

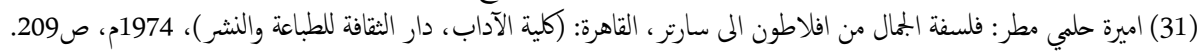

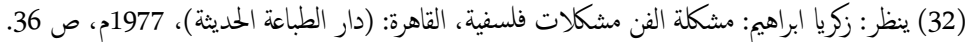

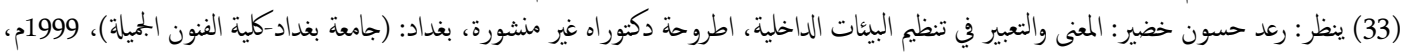


الانسان ، وميل طبيعي لديه، ومحا تنوعت طرائق التعبير واختلفت، فان غايته هي التبليغ والتواصل مع الاخرين ، والتعبير

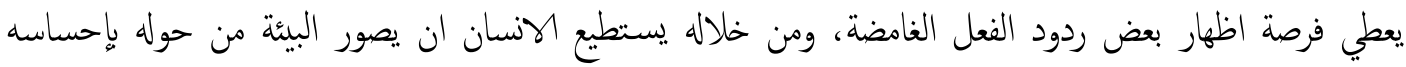

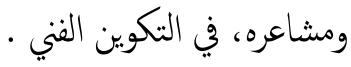
التعبير في فن التمثيل

يعد فن التثثيل واحدا من الفنون الانسانية التعبيرية عن المثقلبات والمتنوعات البيئية بعناوين افكارها وافرادها

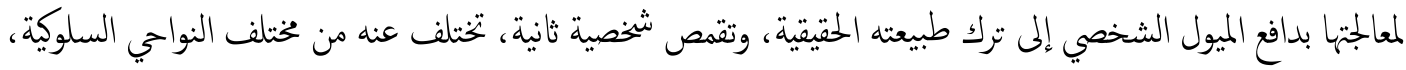

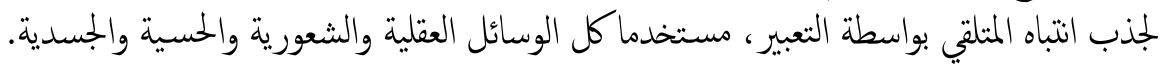

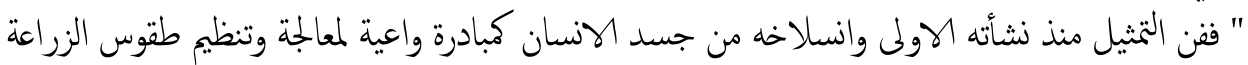

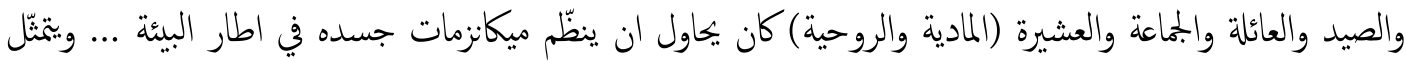

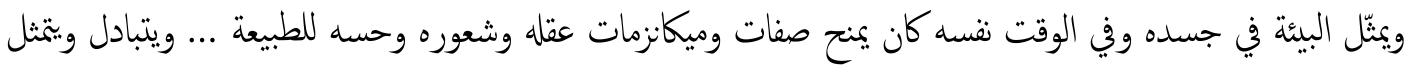

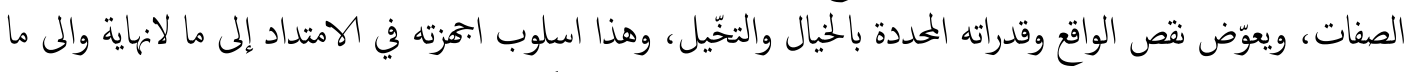

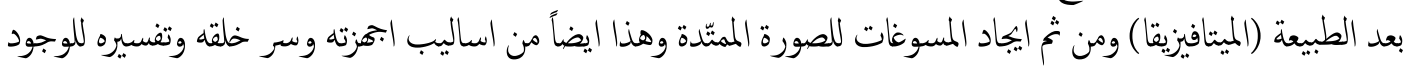
الذاتي والموضوعي" (35) . يعد الفعل والنشاط الإنساني اداة الثفكير والتفاعلات الداخلية للعلاقات الرابطة مع خختلف اشكال المرئيات،

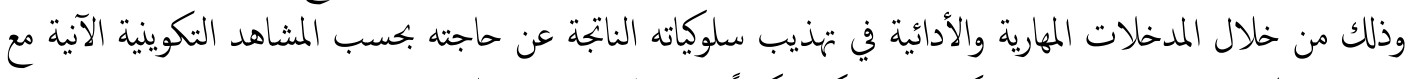

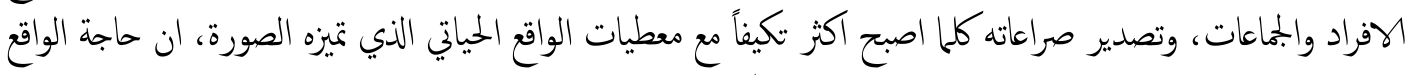

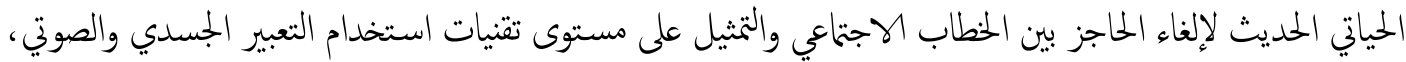

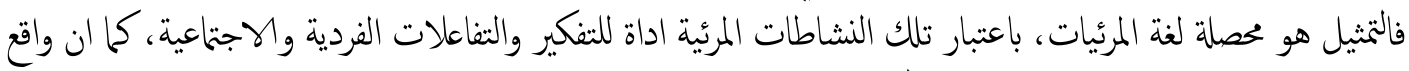

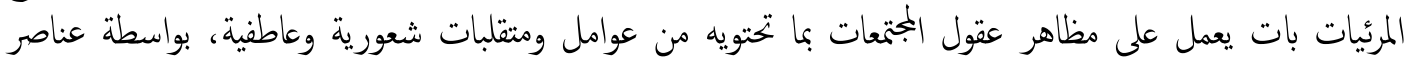

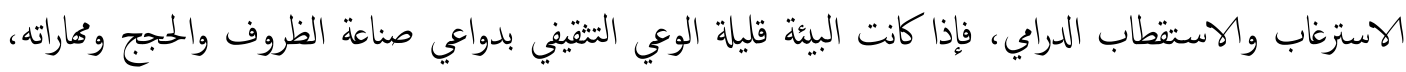

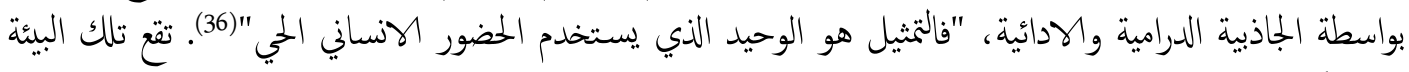

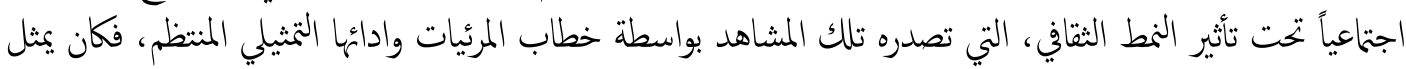

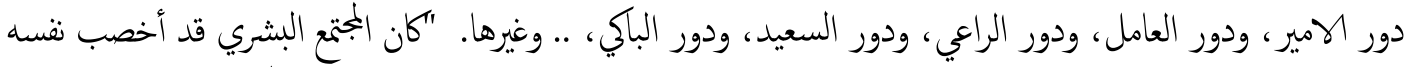

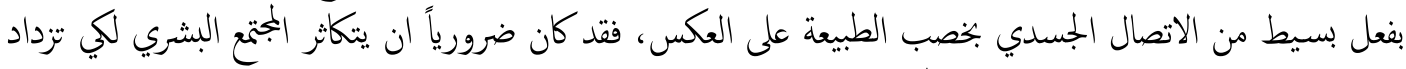

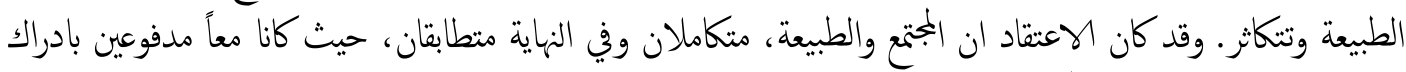

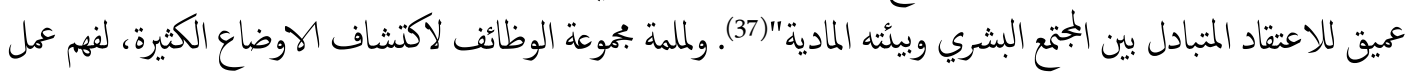

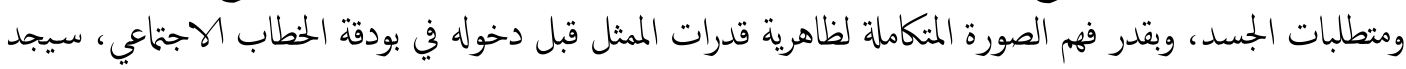

(35) هيثم عبد الرزاق علي: مصدر سابق، 2003م، ص18.

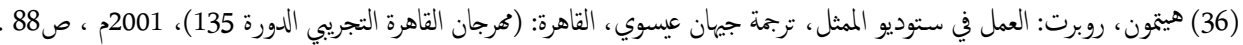

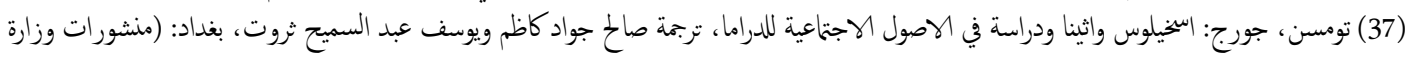




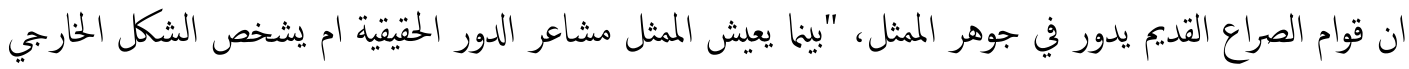
للمعاناة، ظاهرة فن الممثل، والذي هو فعل معرفة و التمثيل فعل بحث عن هوية" (38).

ان مشكلة الممثل هو البحث عن الجسد الاخر، (الجسد المعروض) الدور الذي تتوفر فيه عناصر الاهيهام

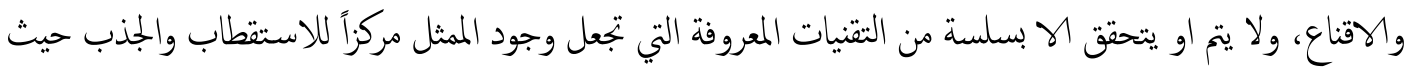

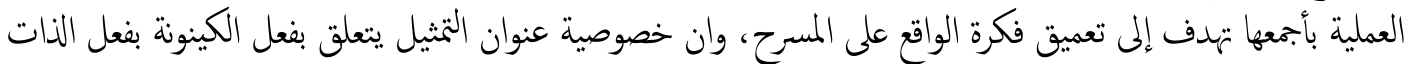

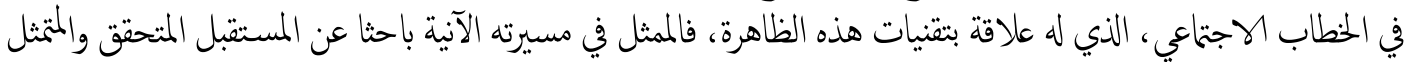

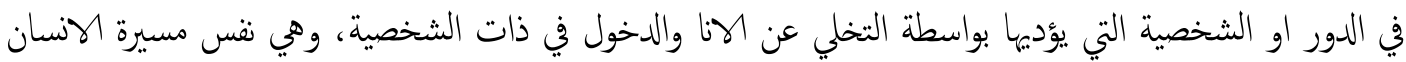

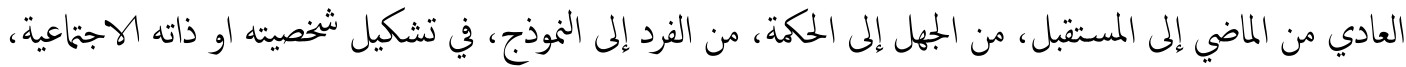

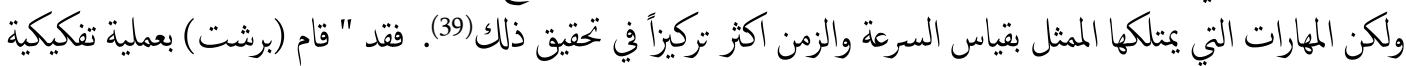

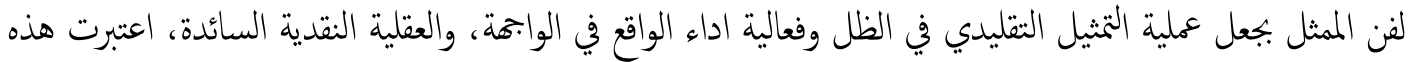

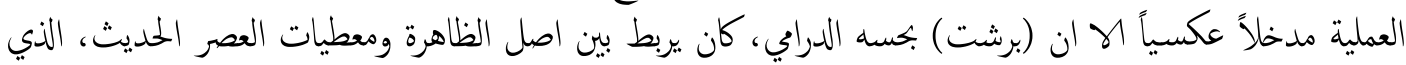

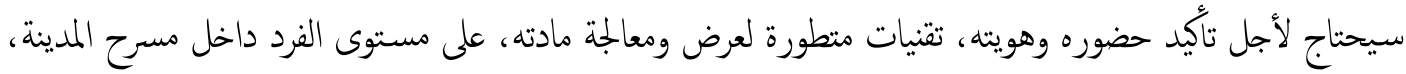

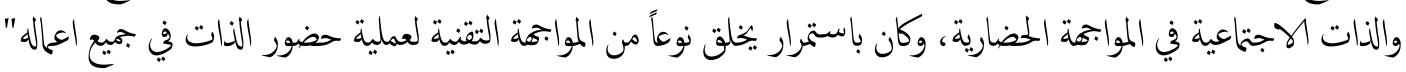

لذا فإن أساس فن التمثيل هو ابتعاد الشخص والانتزاع الكامل عن شخصيته الذانية، وممارسته الشخصية

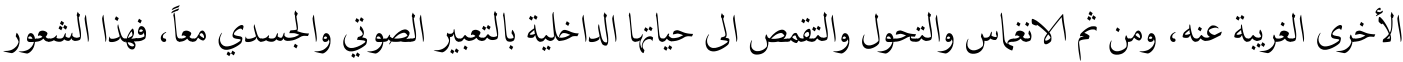

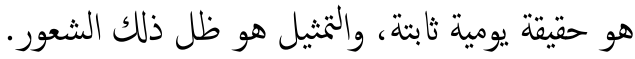

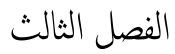

لغرض تحقيق هدف البحث، فقد أتبعت الباحثة المنهج الوصفي التحليلي لتحقيق هدف البحث. منهج البحث: مجتمع البحث: تضمن مجتع البحث (الشخصية)، كظاهرة عامة وأساسية من مظاهر الخطاب التعبيري في فن التمثيل.

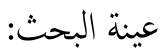

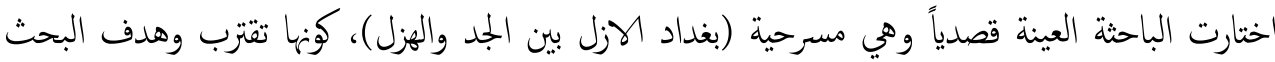

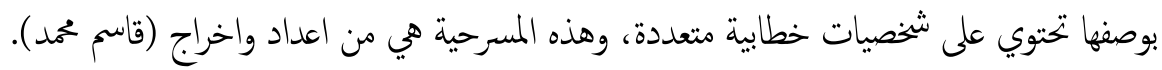

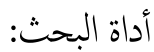

اعتمدت الباحثة في مسار بكثا، الادوات الآتية: (الوثائق، الحبرة الذاتية للباحثة). 
الشخصية ودورها الخطابي التعبيري

ارتبط التمثيل في ذاكرة الشـخصـية العراقية بالتمظهرات الكوميدية التي جاءت من فكرة الهيهام بالواقع رغز ان

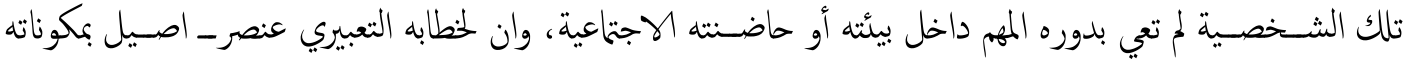
الحياتية ومكنوناته الظاهرية، فللشخصية خطاب تعبيري تلقائي فطري يتوظف مع نشاطه اليومي، قد يفعل اشياءً دون

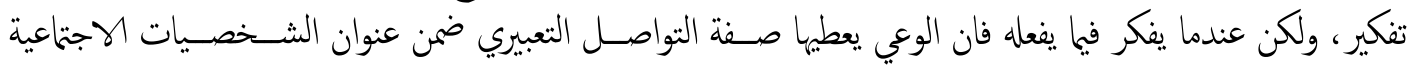

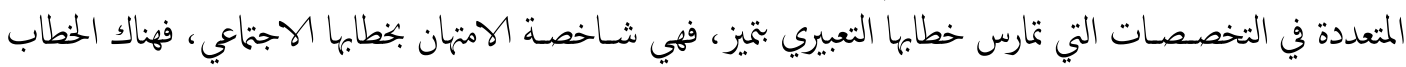

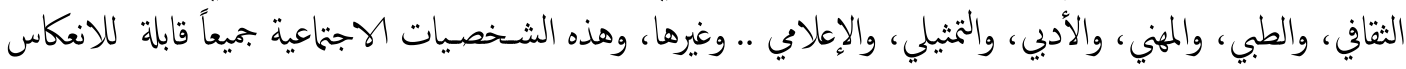

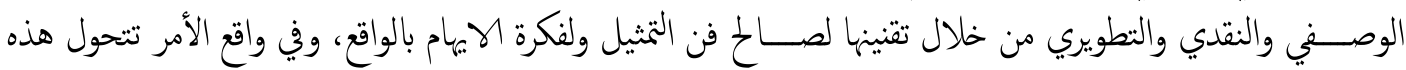

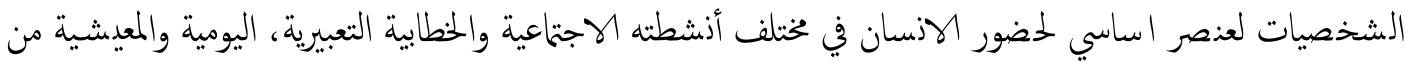

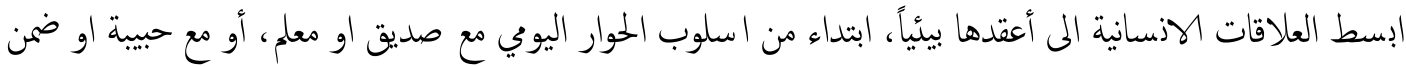

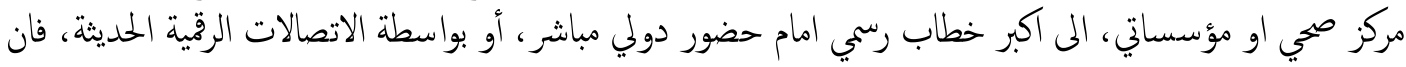

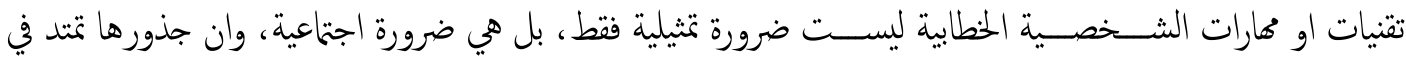
الخطاب الاجتمعي اليومي، فالشخصية الخطابية ضمن التمثيل، تحتوي على عناصر وبيئات بسيطة لنطوير مساحة اداء

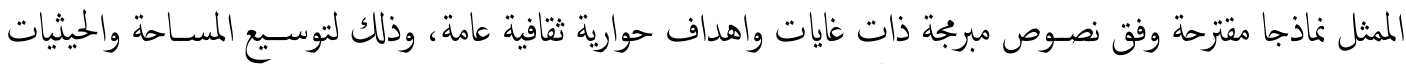

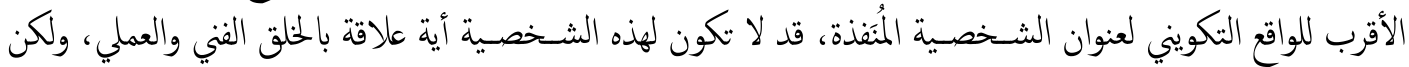

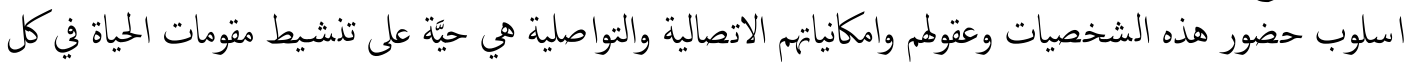

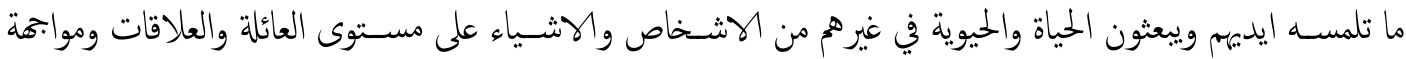

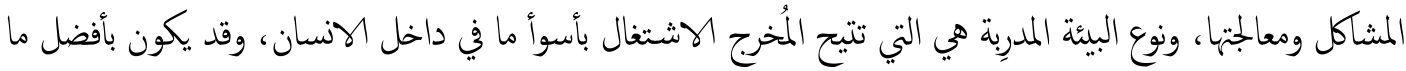

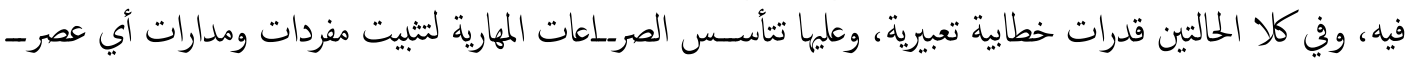

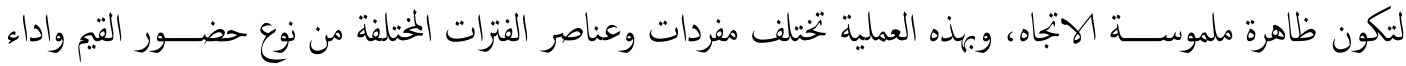

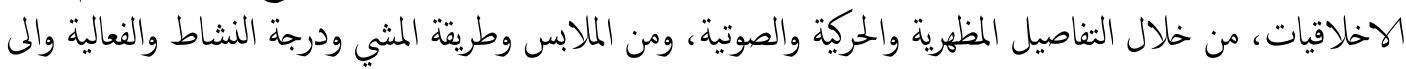

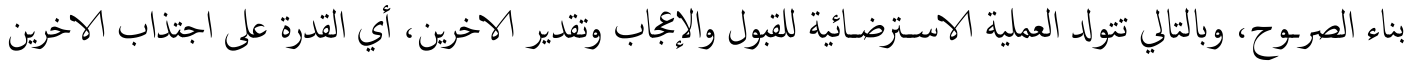

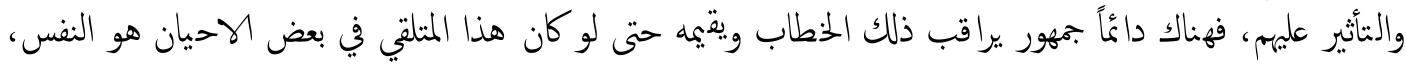

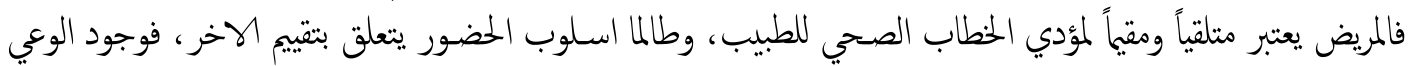

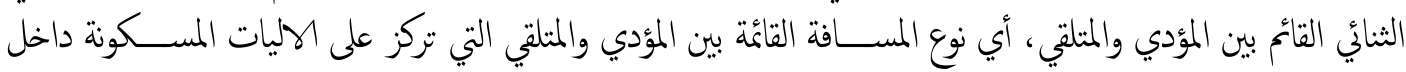

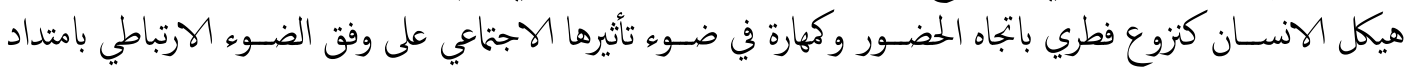

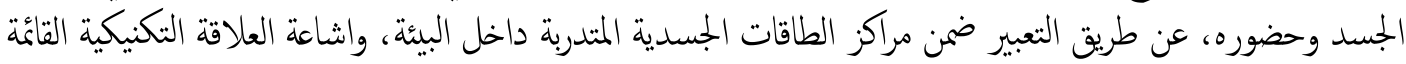

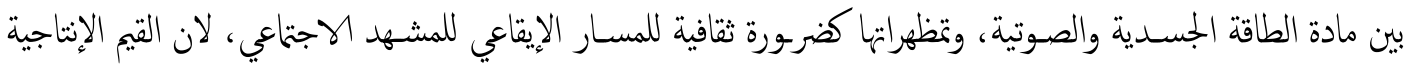

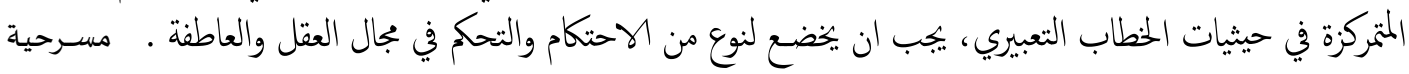

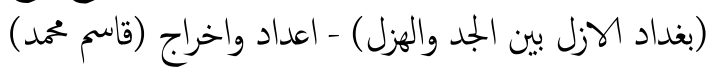

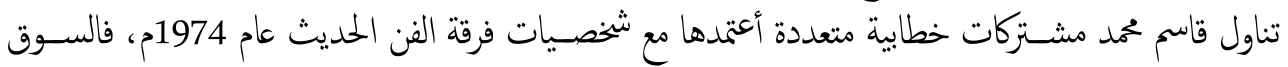
كثكل يجوي مضامين افرزتها تناقضات اجتاعية وصراعات طبتية بين الفقراء الذين يمثلهم الشحاذون والباعة المتجولون والمحتالون على الزمن لكســب قوتهم كالمتطفلين وعلى رأســهم (اشـعب). وفي الجانب الاخر الاغنياء الممثَّين بالأمراء 
والتجار والاقطاعيون واصحاب العقارات، فكانوا وبجا من اوجه تركيز الثروة عند الخاصـــة دون العامة. كلها ظواهر

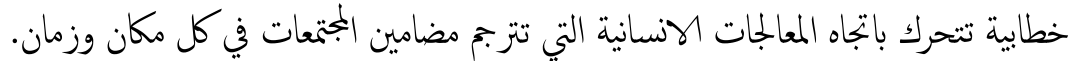

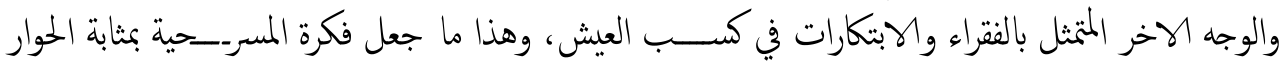

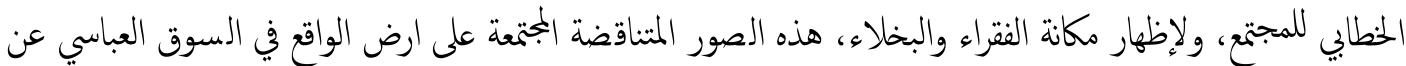

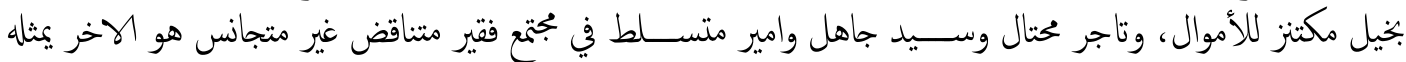

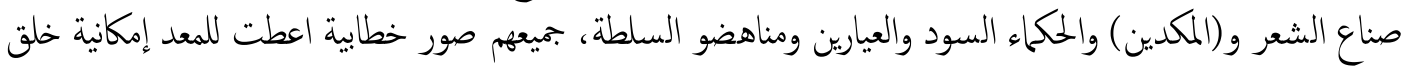

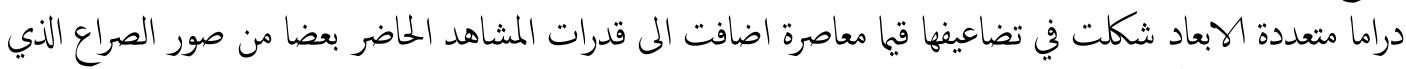

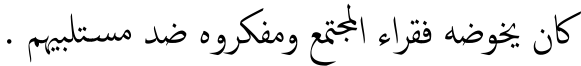
كان ذلك السوق مصوراً لنا فئين سارت بالمسرحين وبنطين متوازيين كل منها يحمل حوارات خطابية واجبة

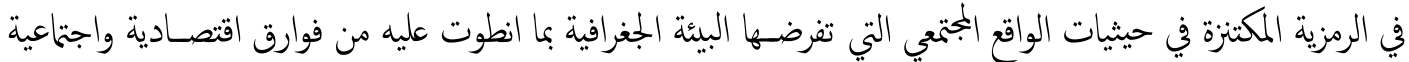

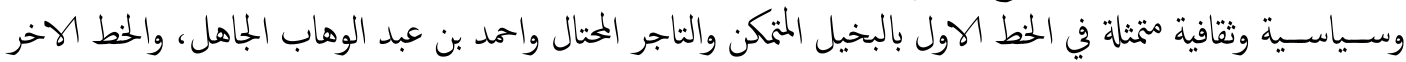

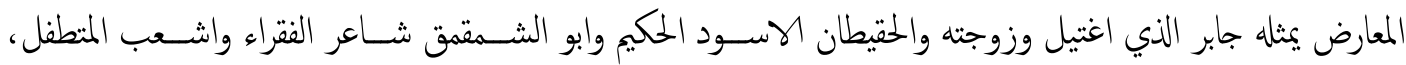
والعيار المناضل وغير هم من الفقراء. تنبعث من مركات الاحداث، الناكيدات على مبدأ الوفرة في النماذج دون التركيز على شخصية واحدة او حدث

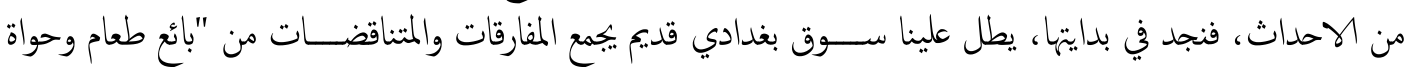

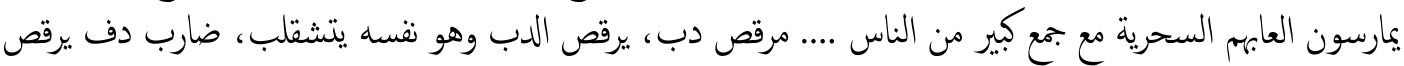

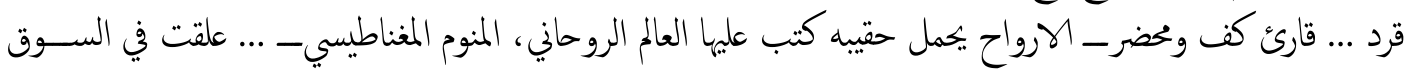

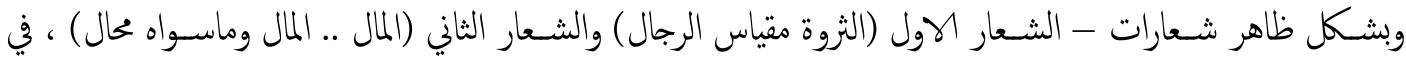
السوق عدد من الشحاذين والصعاليك واللصوص والطفيلين"(41).

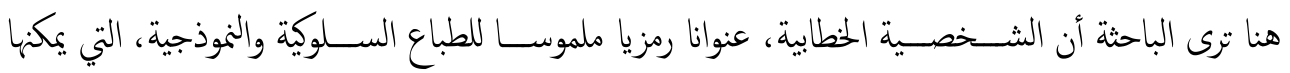

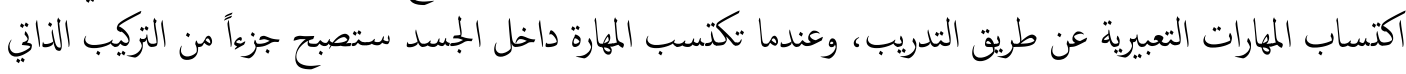

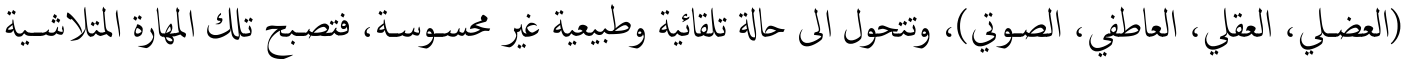

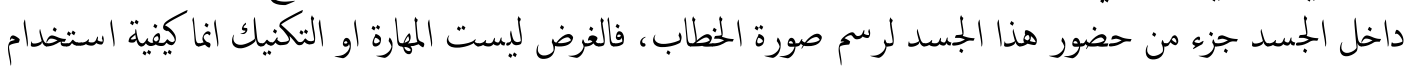

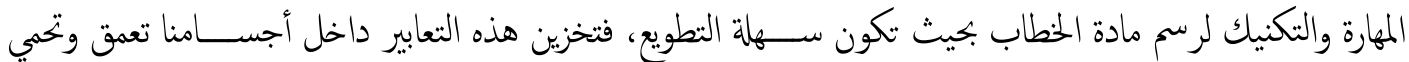
خطاب الانسان وحضوره، ولكن تخزين هذه المهارات في هيكل الممثل هو تعميق ميله الشخصي لترك شخصيته الذاتية

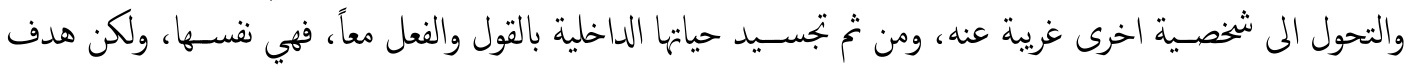

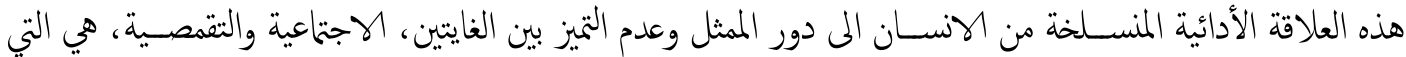

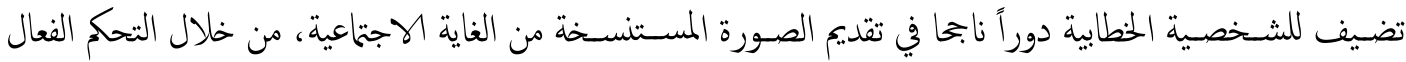
لتصبح ضرورة الافتعال الخطالي من خلال الجسمد بأبعاده ومقاساته، وطريقة اللبس والتسريحة والتعامل بوا سطة العين

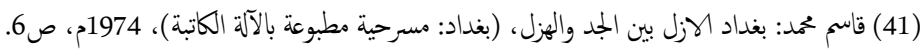

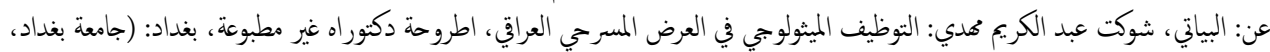




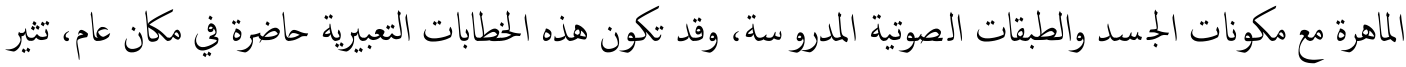

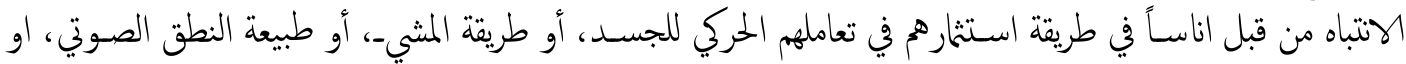

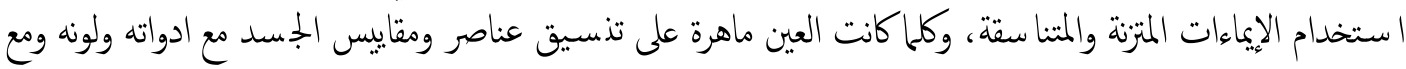

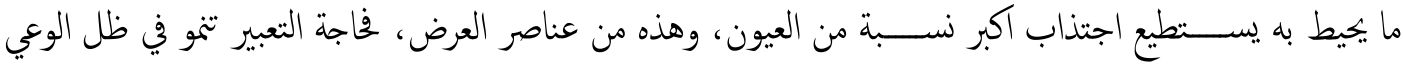

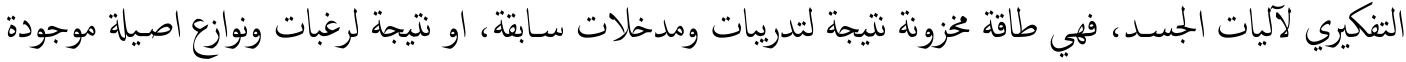

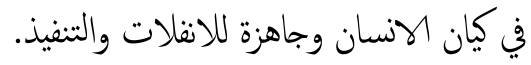

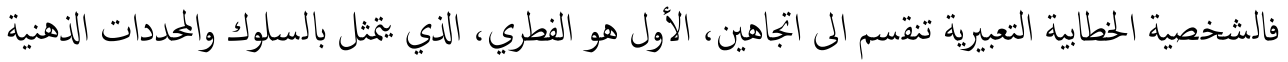

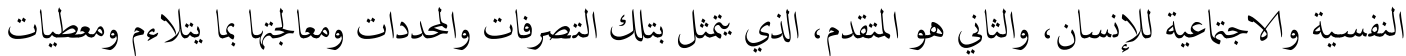

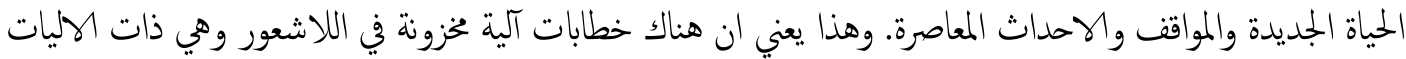

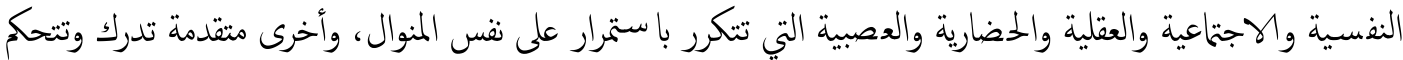

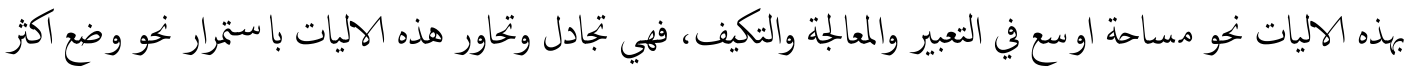

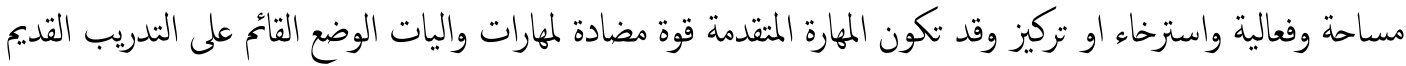

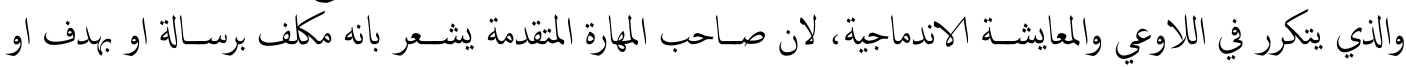

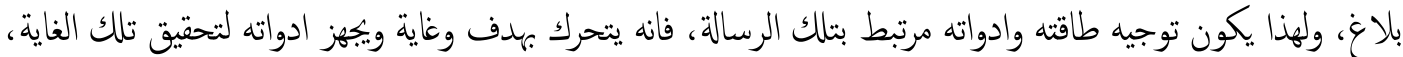

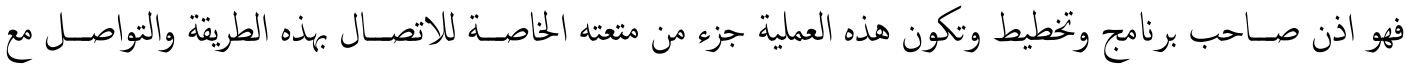
المواقف والهداث.

نتابُ البحث

1- - ارتباط فن التمثيل في الخطاب التعبيري بالشخصية من خلال فكرة الاهيهام بالواقع.

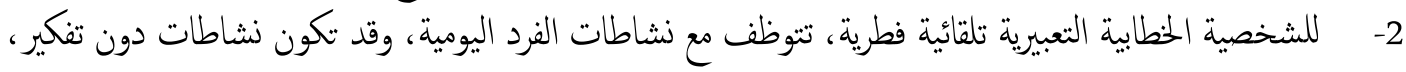

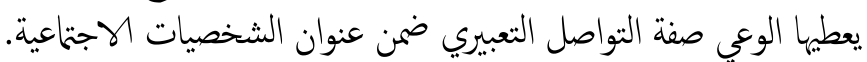

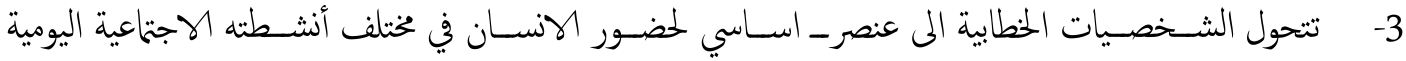
والمعيشية، من ابسط العلاقات الانسانية الى أعقدها بيئياً.

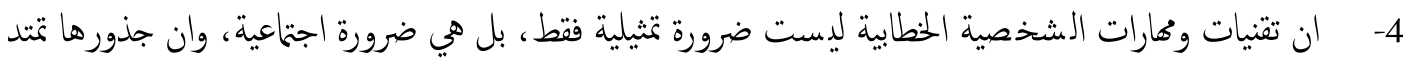

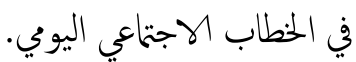
5- ان الشخصية الخطابية ضمن التمثيل، تحتوي على عناصر وبيئات بسيطة لتطوير مساحة اداء الممثل نماذجا مقترحة وفق نصوص مبرجة ذات غايات واهداف حوارية ثقافية عامة.

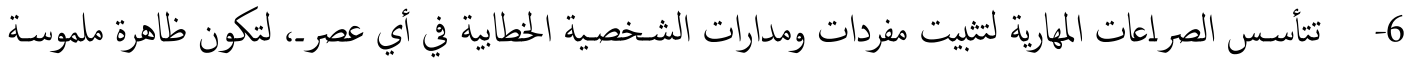

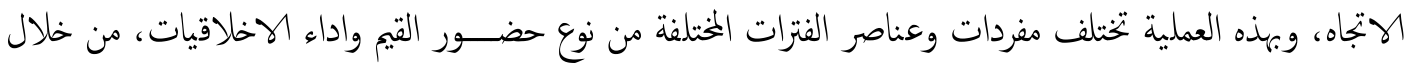
التفاصيل المظهرية والحركية والصوتية.

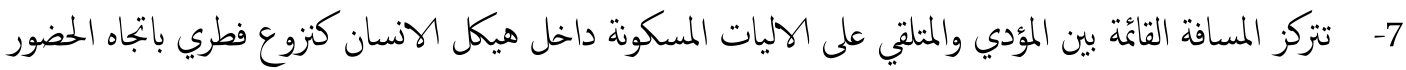

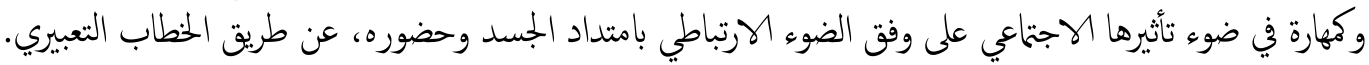
8- لا بذْ ان يخضع الخطاب التعبيري لنوع من الاحتكام والتحكم في مجال العقل والعاطفة. 
9- تعتبر الشخصية الخطابية، عنوانا رمزيا ملموسا للطباع السلوكية والنموذجية، التي يمكنها اكتساب المهارات التعبيرية عن طريق الندريب، والتي ستصبح جزءاً من التزكيب الناتي.

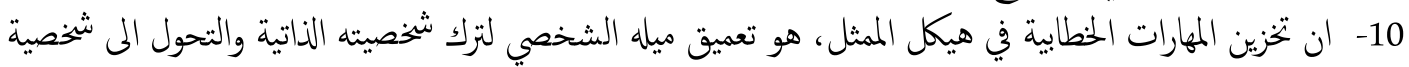

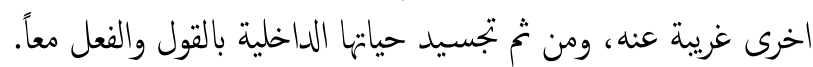

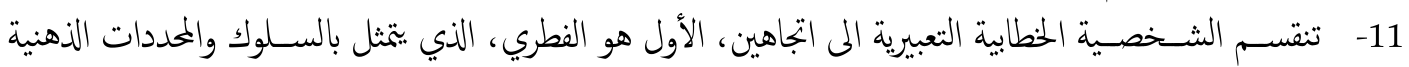

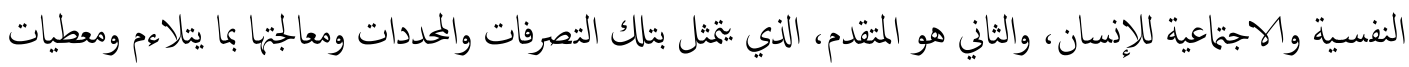

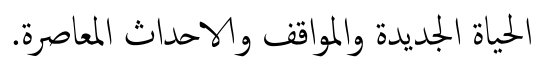

التوصيات والمقترحات

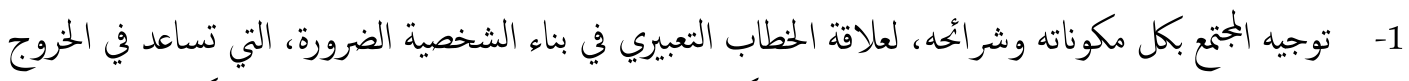

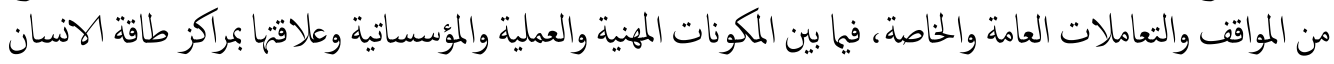
الانتاجية. 2- المتداد في ثقافة الخطاب التعبيري في فن التثثيل، بكونه عنوان الثقافة والحضارة البيئية والمحاية من التوبجات الملتوية المضادة، لاختراق تلك الأصول العريقة. 3- وضع أنظمة ودورات وفرضيات تدريبية، مباشرة وغير مباشرة، تتوفر فيها عناصر التسلية لتنشيط وتوسيع مساحة الخطاب التعبيري وتقوية شخصية الفرد اجتماعيا وثقافيا وتخصصيا. 


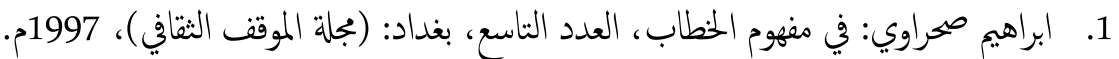

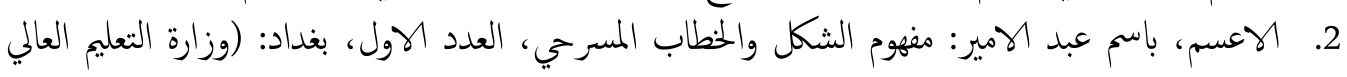

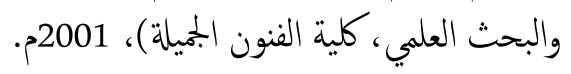

3. اميرة حلمي مطر: فلسفة الجمال من افلاطون الم سارتر ، القاهرة: (كلية الآداب، دار الثقافة للطباعة والنشر)،

1974م

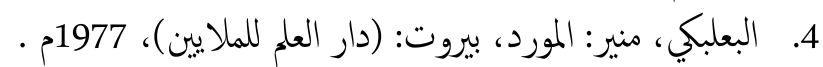

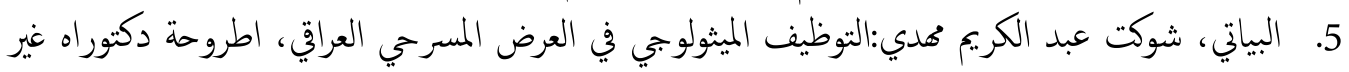

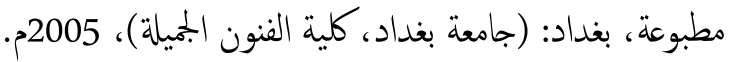

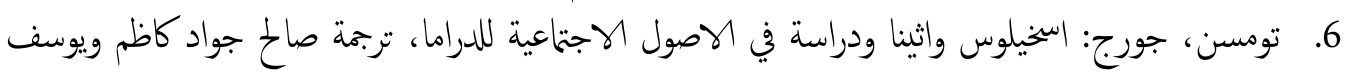

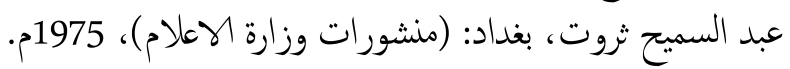

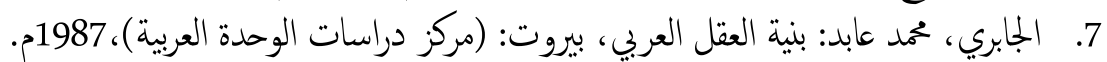

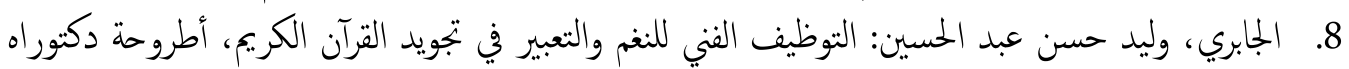

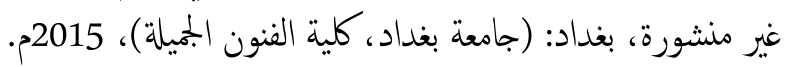

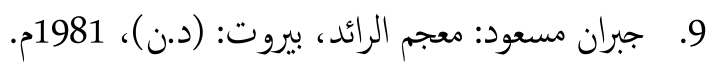

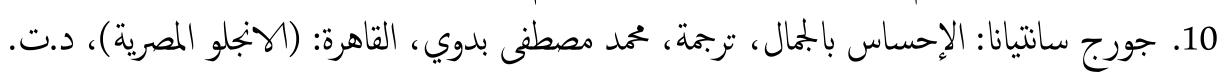

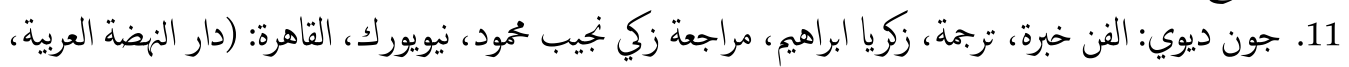

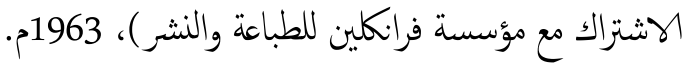

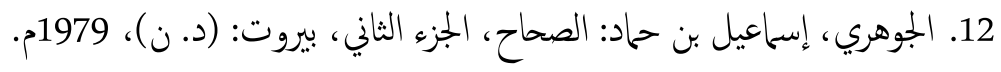

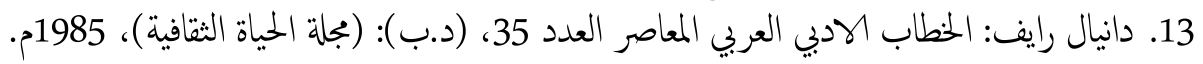

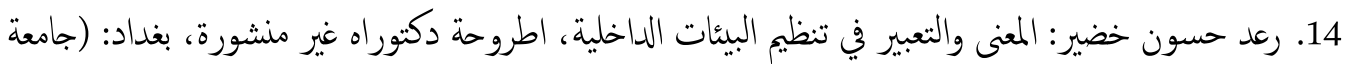

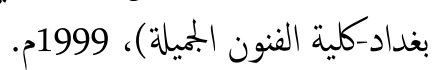

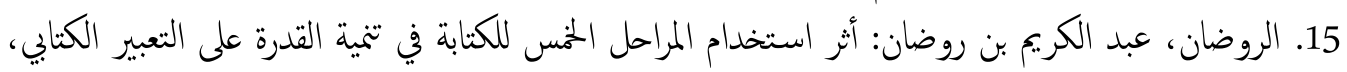

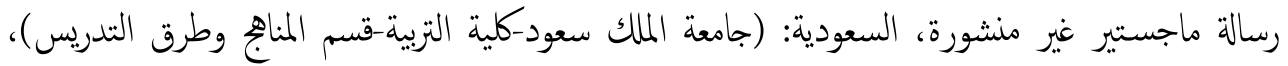
2008

16. زاخوافا، بوريس: فن الممثل والمخرج، ترجمة عبد الهادي الراوي، الطبعة الهولى، الاردن: (منشورات وزارة الثقافة)، 1996م.

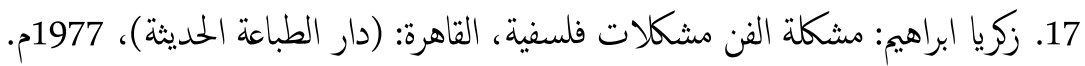

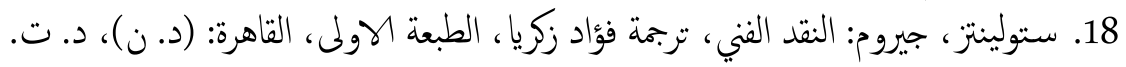

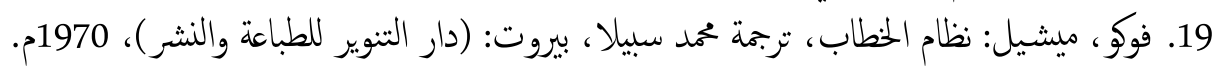

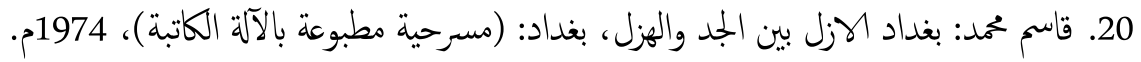

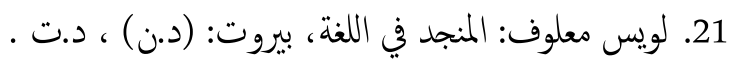


22. الماكري، محمد: الشكل والخطاب، مدخل لتحليل ظاهراتي، الطبعة الأولى، بيروت: (المركز الثقافي العربي)،

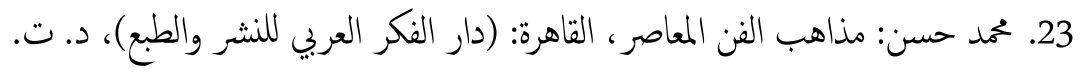

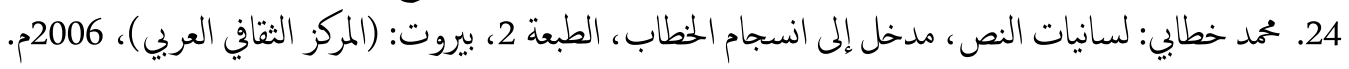

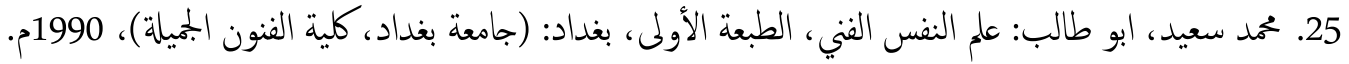

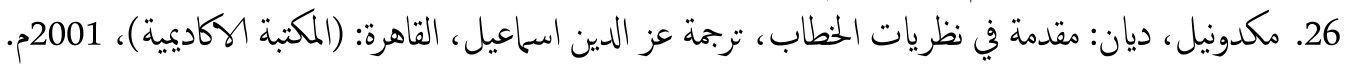

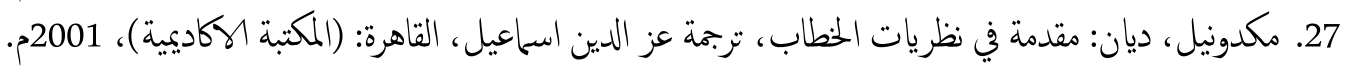

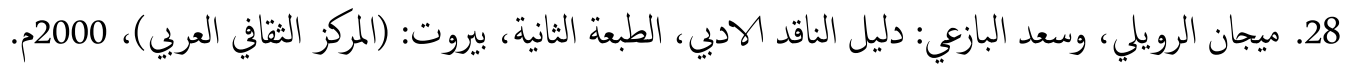

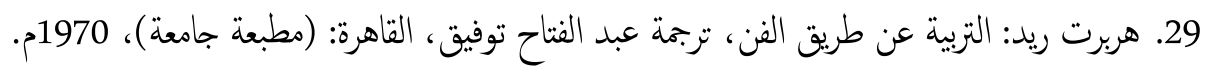

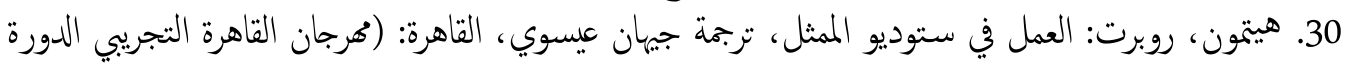

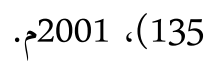

31. هيثم عبد الرزاق علي: محارات فن الاداء في التثثيل والخطاب الاجتماعي، أطروحة دكتوراه غير منشورة،

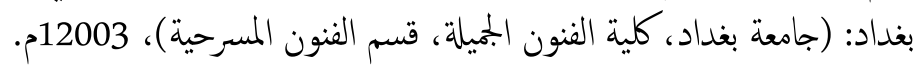




\section{Expressive speech in the art of acting}

\section{Ghada Abdal_Sattar Awad}

\section{University of Baghdad \College of Fine Arts}

\section{Abstract}

The expressive speech in the art of acting is considered to be the leading action for thinking and the interior interaction of the individual, in the organization of his relationship with the elements of the environment and its content, and the more acquired the individual's performance today skills in organizing and export of his conflicts and natural occasions, whenever, becomes more adaptable and an interpreted physically and acoustically inside pluralities in personalities, suited to the modern age. This research has addressed a range of topics related to expressive speech in the art of acting, since the first chapter included a systematic framework of the research, represented by the problem, the importance and aims of research to detect speech expressionist being a need for cultural environments and address of societies and civilizations. The second chapter, it was within the theoretical framework, represented by the following axes: (concept of speech, the concept of expression, and expression in the art of acting). While the third chapter included a description of analytical personality, being a part of the subject of discourse in the expressionist art of acting, and reached a number of conclusions and made a number of recommendations and suggestions and finally research ended with a list of sources. 